دور تقانة المعلومات والاتصالات في تعزيز الريادة الشخدية

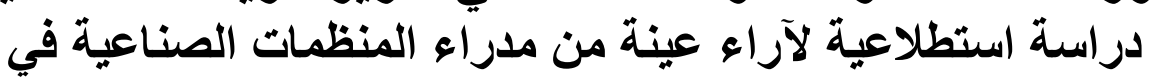
محافظة نينوى مدر من

\author{
ربيع علي زكر \\ مدرس مساعد - قسم نظم المعلومات الإدارية \\ كلية الإدارة والاقتصاد - جامعة الموصل
}

Rabeeali78@yahoo.com

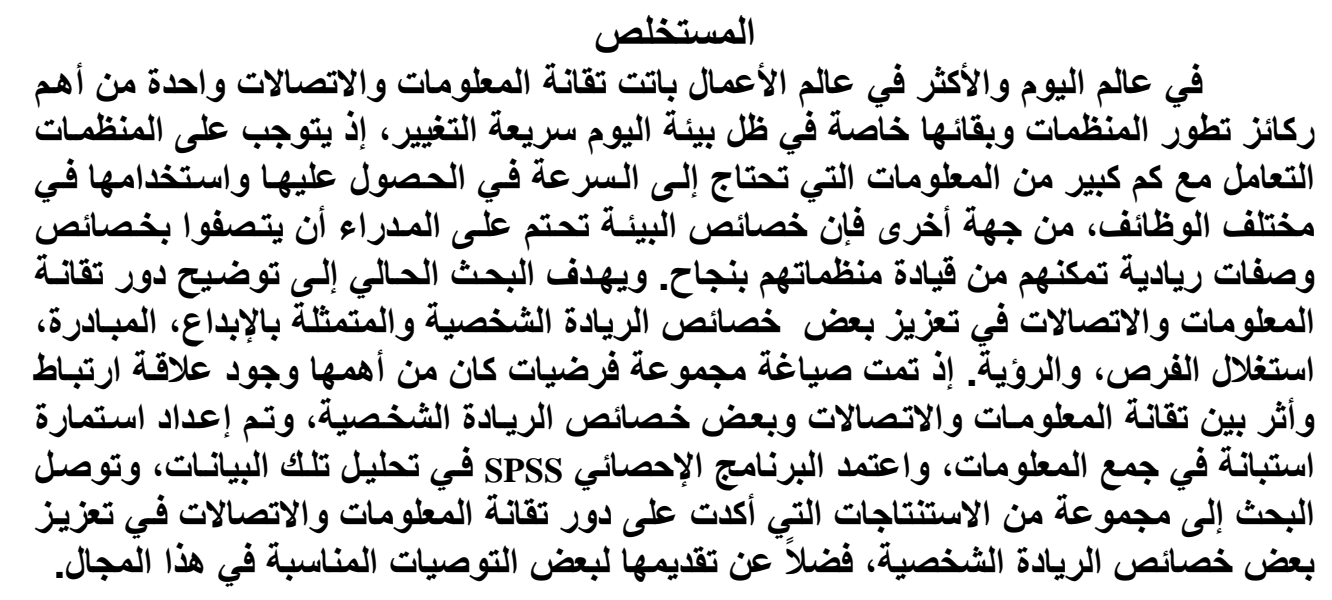

الكلمات المفتاحية: تقانة المعلومات والاتصالات، الريادة، الريادة الثخصية. 


\title{
The Role of Information and Communication Technology in Reinforcement of Personal Entrepreneur A Pilot study for Opinion of A Sample of Industrial Organizations Managers in Mosul Province
}

\author{
Rabee Ali Zaker \\ Assistant Lecturer \\ Department of Management Information Systems \\ University of Mosul \\ Rabeeali78@yahoo.com
}

\begin{abstract}
In today's world and the most in the business world are the information and communications technology (ICT) is one of the most important pillars of development organizations. Their survival is especially stood in light of today's environment of rapidly changing. The organizations must deal with a large amount of information which needs to speed access and use in different jobs. On the other hand, the characteristics of the environment make it mandatory for managers for pioneering characteristics and the qualities of entrepreneurial to enable them to lead their organizations successfully. The current research aims to clarify the role of ICT in promoting some of the characteristics of entrepreneurial such as personal creativity, initiative, opportunities, and vision. It has to formulate a set of hypotheses were important entity to correlate the effect of information communication technology and some personal characteristics of entrepreneur. A questionnaire has been prepared, and data collection was adopted, statistical program (SPSS) in analyzing such data has been reached to a set of conclusions which emphasized the role of information communication technology in promoting some of the characteristics of personal entrepreneurial, as well as providing some appropriate recommendations in this area.
\end{abstract}

Keywords:

Information Communication Technology, Entrepreneurship, Personal Entrepreneur.

المقدمة

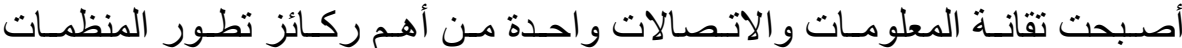

وبقائها، إذ باتت تمثل المحرك الأساسي لعمل هذه المنظمات خاصسة في ظل البيئة المتسمة

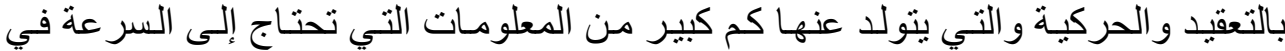

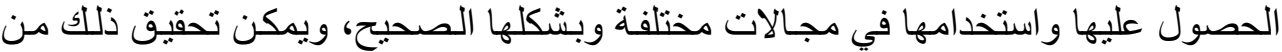

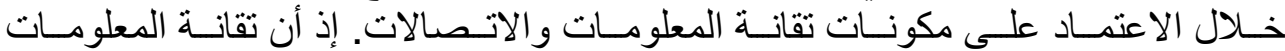

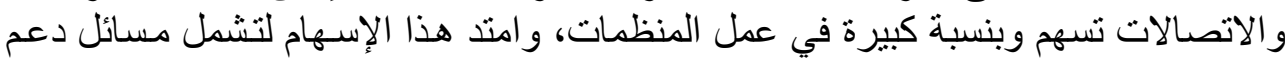
وتعزيز الصفات و الخصائص الثخصية للأفر اد العاملين في مختلف المستويات التظظيمية

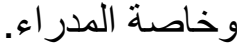

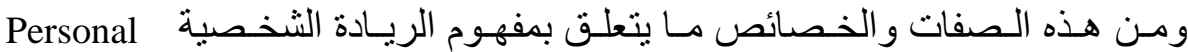
Entrepreneur المفكرين والبـاحثين في المبـادين الإداريـة والاقتصادية. ولقد ازداد الاهتمـام بمفهوم الريـادة 


\section{ز9)}

الشخصية في الوقت الحالي كونه يعد أحد أهم أسباب النمو في المجتمعات من وجهة نظر الكتاب و الباحثين أمثال فateman, Robert, Daft

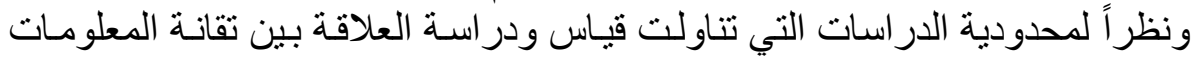

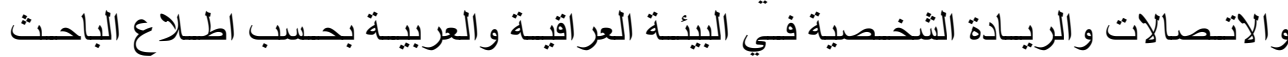

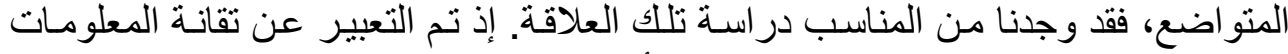

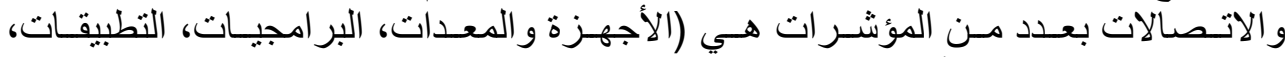

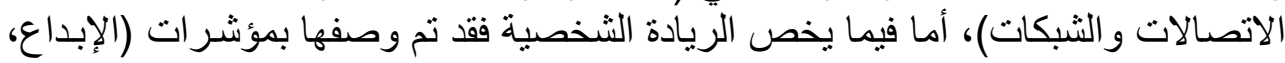

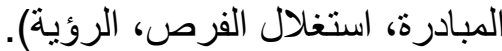

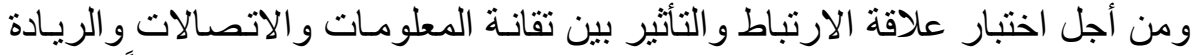

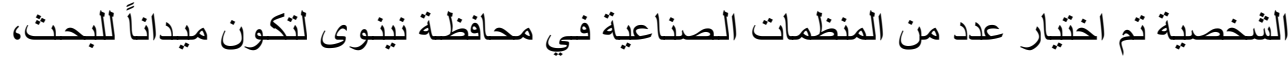

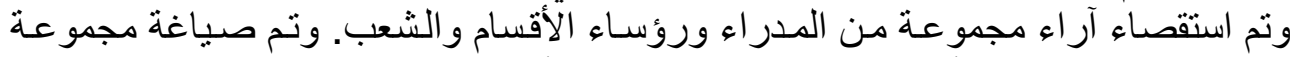

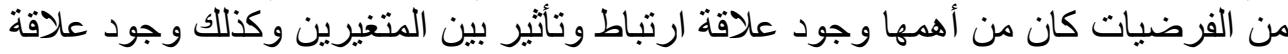

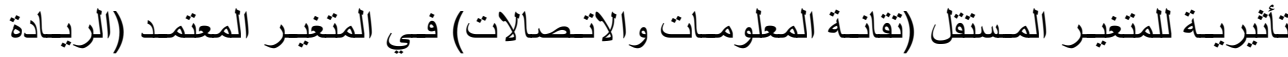

الثخصية).

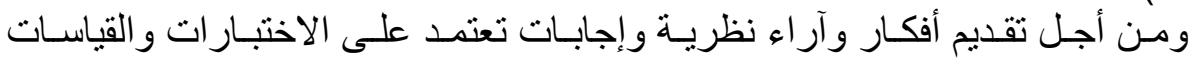

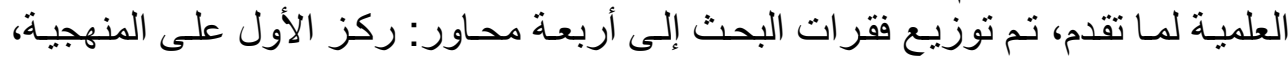

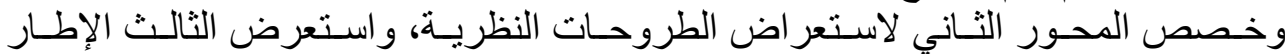
الميداني للبحث، وجاء المحور الرابع ليتضمن الاستنتاجات والتورات التوصيات.

\section{المحور الأول- منهجية البحث

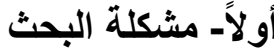

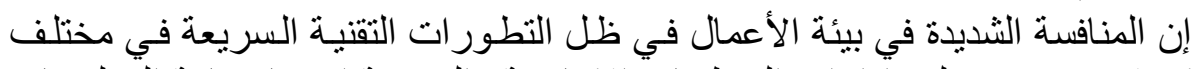

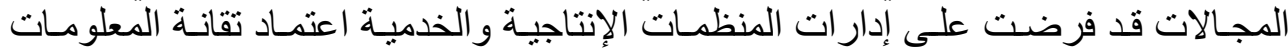

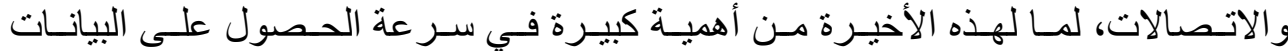

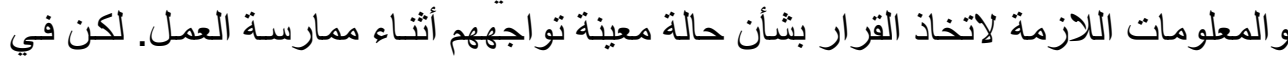

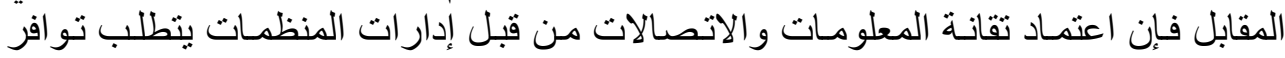

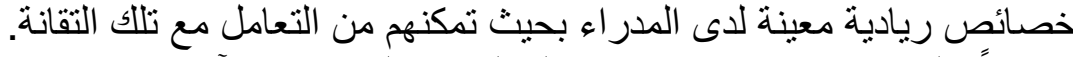

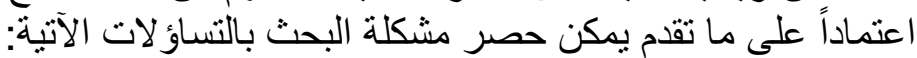

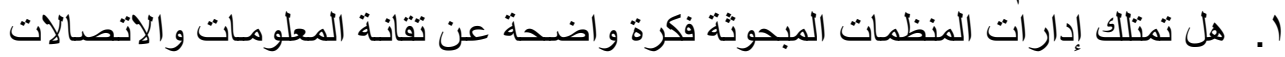

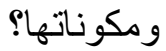

r. . هل تمنلك إدار ات المنظمات المبحوثة فكرة و اضحة عن خصائص الريادة الشخصية؟

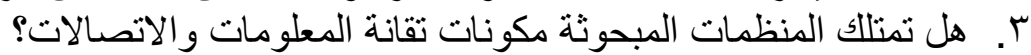

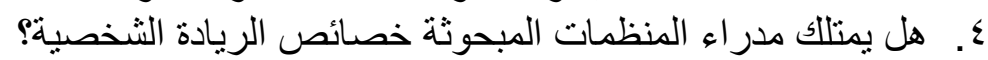

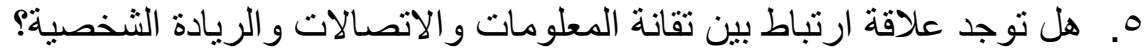

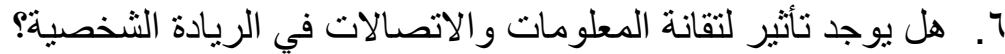




$$
\text { ثانياً- فرضيات البحث }
$$

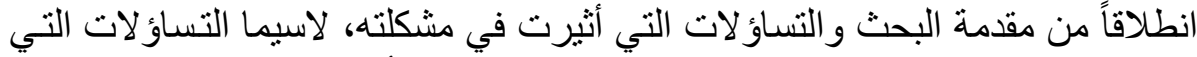

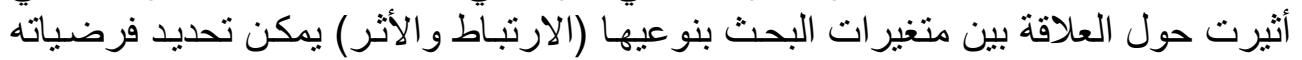

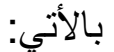
ا ـ توجد علاقة ارتباط معنوية بين تقانة المعلومات و الاتصالات و الريادة الثخصية. وتنبثق عنها الفرضيات الفر عية الآتية:

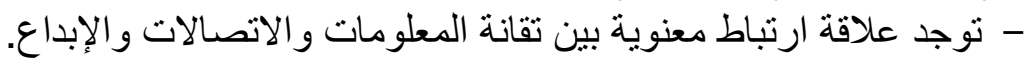

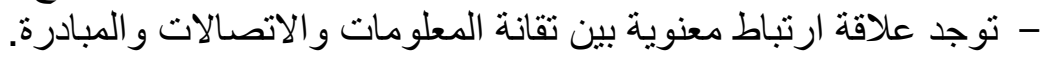

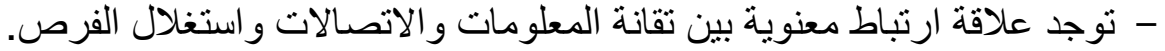

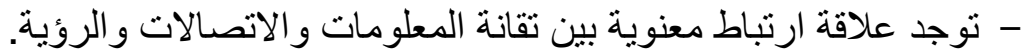

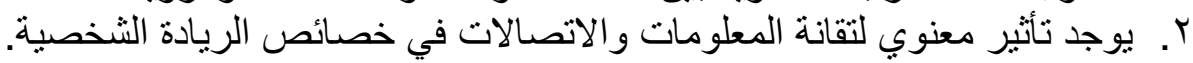
وتنتئق عنها الفرضيات الفرية عية الآتية: - يوجد تأثير معنوي لتنقانة المعلومات و والاتصالات في في الإبداع.

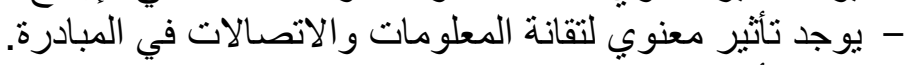

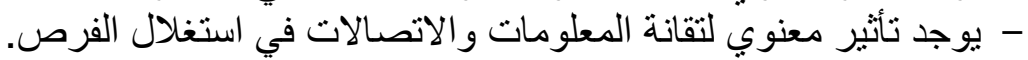
- يوجد تأثير معنوي لتنقانة المعلومات و الاتصالات في الرؤية.

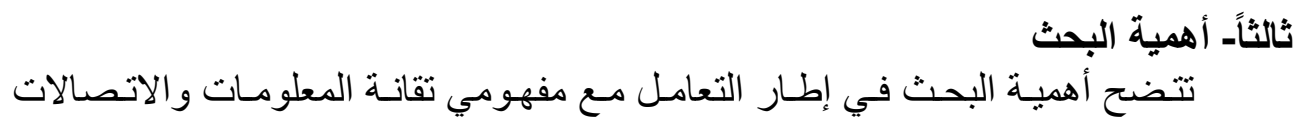

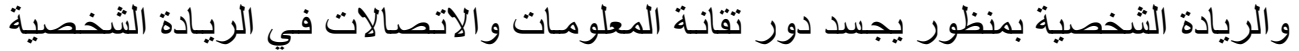

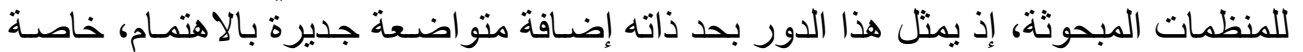

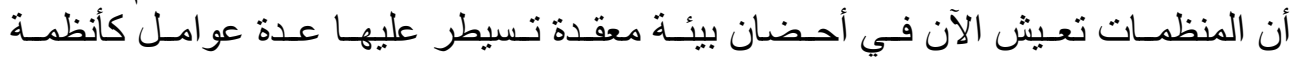

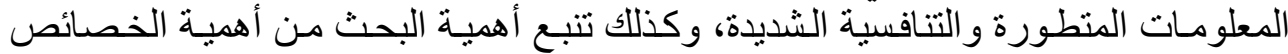

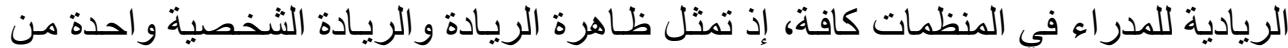

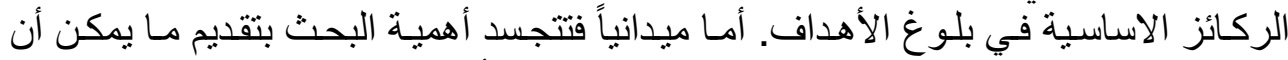

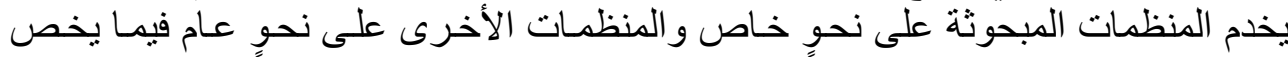
العلاقة بين تقانة المعلومات و الاتصـالات و الريادة الثخصية.

رابعاً- أهداف البحث

1. تقليم إطار نظري لمفهومي تقانة المعلومات وافي الاتصالات و الريادة الثخصية.

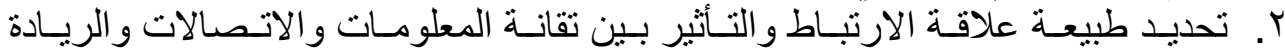

الثخصية.

خامساً أساليب جمع البيانات

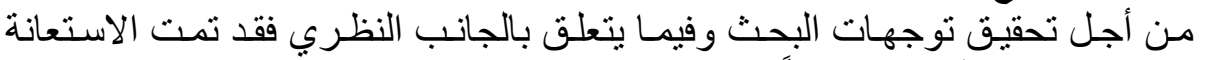

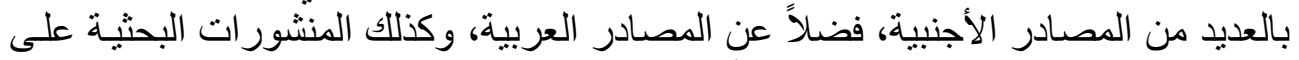

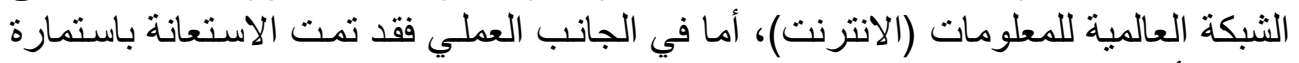

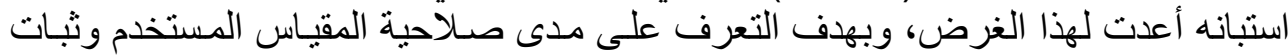
الاستبانة فقد تم استخدام مقياس (كرومباخ آلفا)، واتضح أن معامل (آلفا) كان (0.77) على السى 


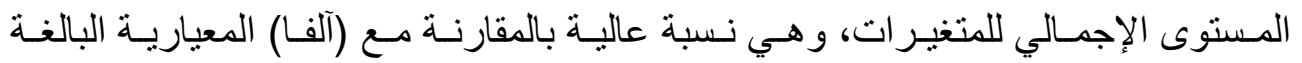

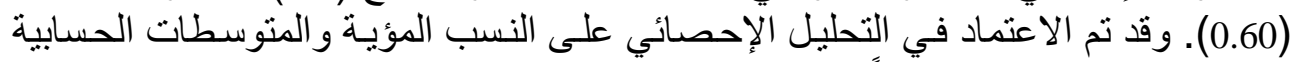

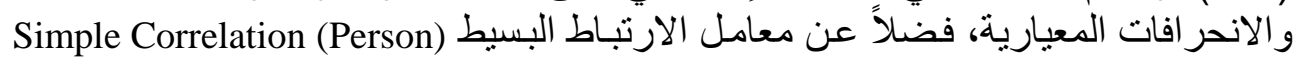

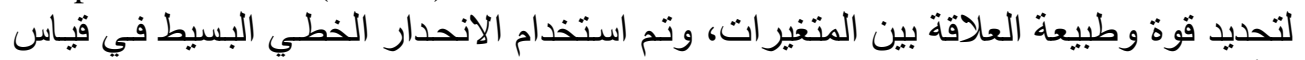
التأثنر المعنوي للمتغير المستقل في المتغير المعتمد.

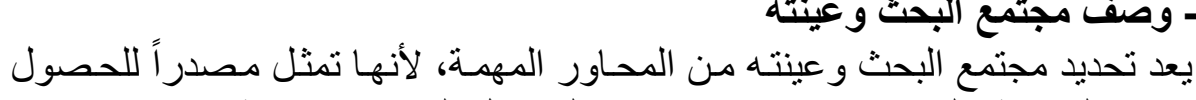
سادساً وصف مجتمع البحث وعينته

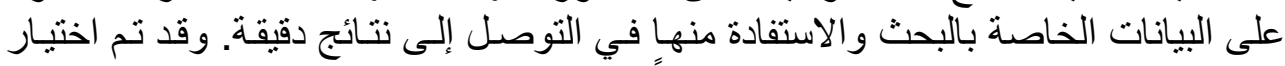

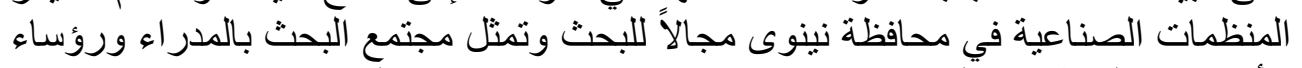

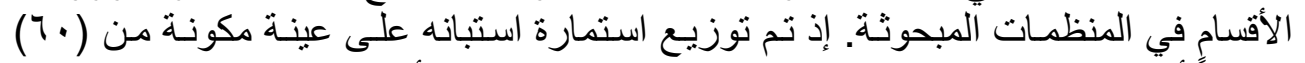

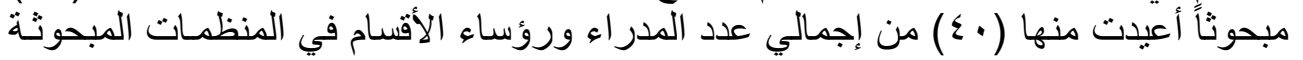

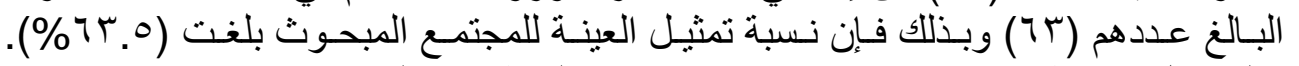

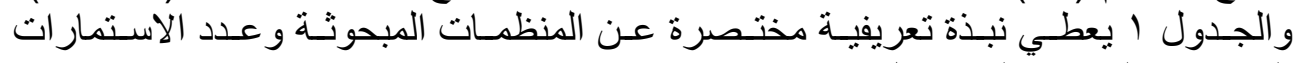
الموزعة و المستحصلة في كل نون منها.

\begin{tabular}{|c|c|c|c|c|c|c|c|}
\hline \multicolumn{8}{|c|}{ تعريف مبسط بالمنظمات المبحوثة وعدد الاستمارات الموزعة والمستحصلة } \\
\hline \multirow{2}{*}{ نسبة تمثيل } & \multirow{2}{*}{ مرؤسموع المدراء } & \multicolumn{2}{|c|}{ الاستمارات } & \multirow{2}{*}{ 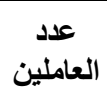 } & \multirow{2}{*}{ 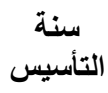 } & \multirow{2}{*}{ اسم المنظمة } & \multirow{2}{*}{$ت$} \\
\hline & & المستحصلة & الموزعة & & & & \\
\hline$\% 77.7$ & rV & 11 & ro & $r \ldots$ & 1914 & الألسبـة الجـاهزة العامـة لـــــاعة & 1 \\
\hline$\% 9 \cdot .1$ & 11 & 1. & 1. & $\wedge$. & $191 \mathrm{r}$ & شركة الخازئة لإتتاج المواد & $r$ \\
\hline$\% \leqslant \wedge$ & ro & Ir & ro & $18 \ldots$ & $19 V$. & المشراق الـشة العامــة لكبريـــت & $r$ \\
\hline
\end{tabular}

المصدر: من إعداد الباحث في ضوء استمارة الاستبانة.

أ. المنصب الوظيفي: يتضح من الجدول ب أن غالبية المبحوثين هم من رؤسـاء الأقسام

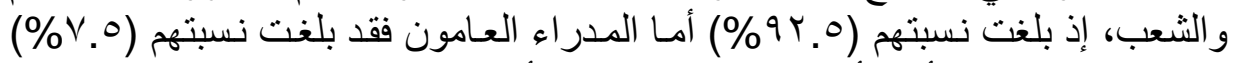

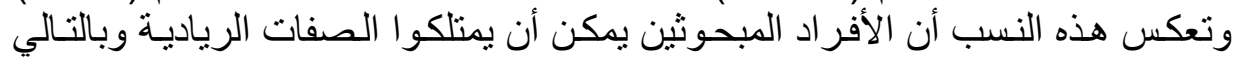

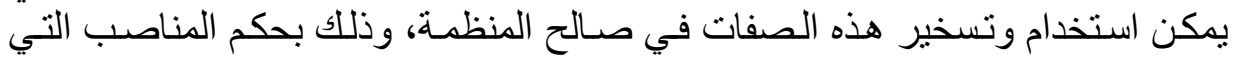
يتمتعون بها.

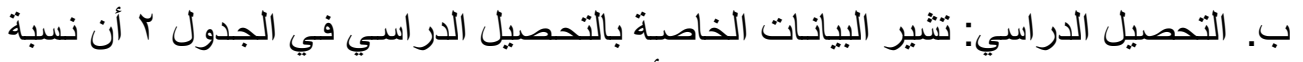

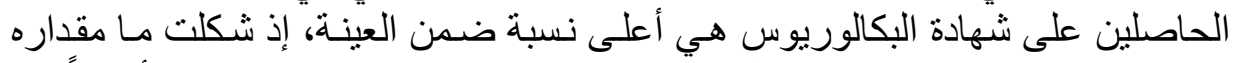

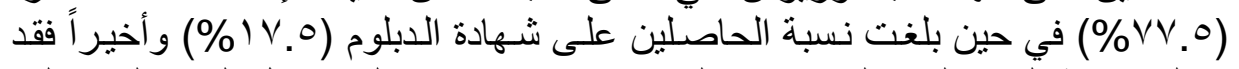

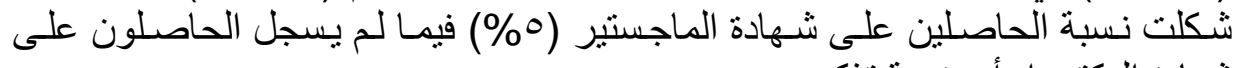

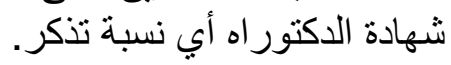

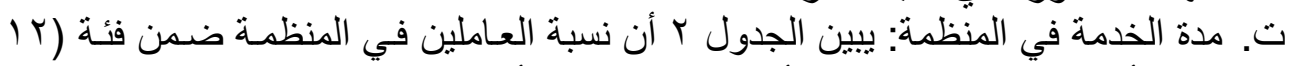

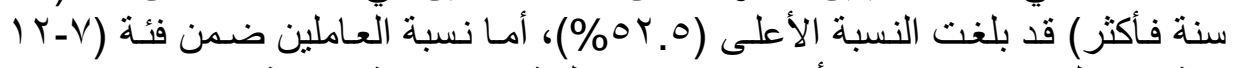

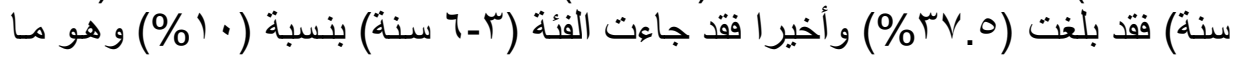


يعكس مدى اطلاع الأفر اد المبحوثين وخبرتهم و إمكانية اتصافهم بالصفات الرياديـة في

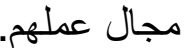

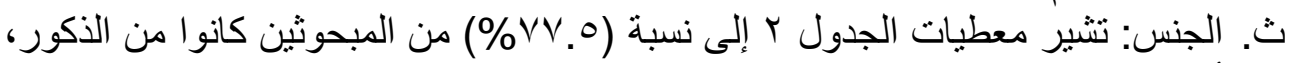

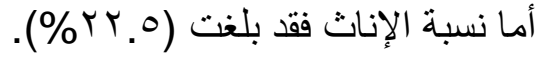

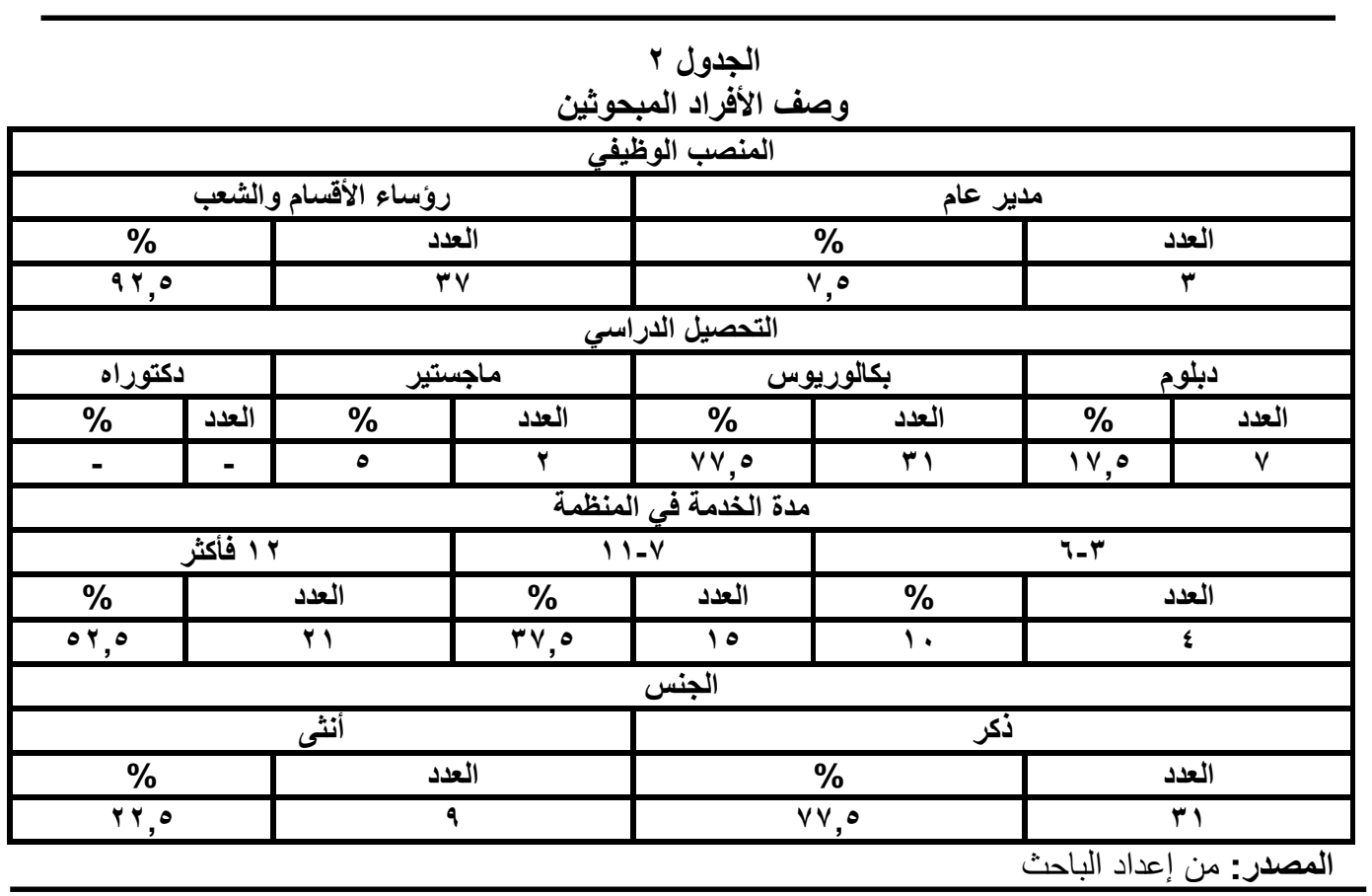

\section{المحور الثاني- الإطار النظري

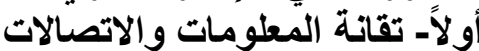 1 ـ مفهوم تقانة المعلومات واتل والاتصالات الاتات}

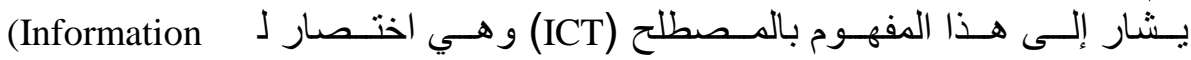
Communication Technology) وبحسب خلفيتهم العلمية والزاويـة التي ينظر من خلالها، إذ يرى (Efraim et al, 1996, 9)

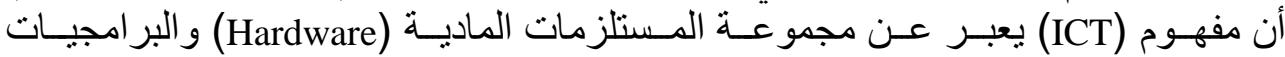
(التي تخدم وسائل الاتصال المختلفة، في حين يرى (Software)

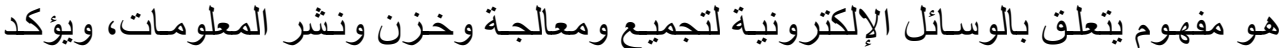
(Daft, 2001, 573)

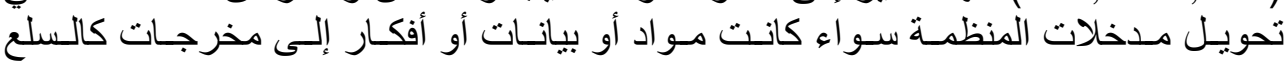

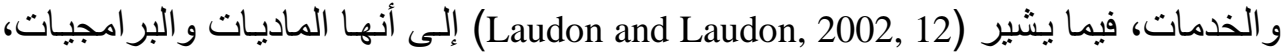

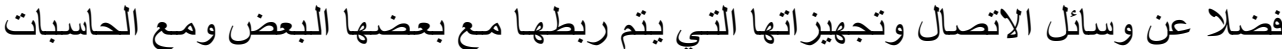

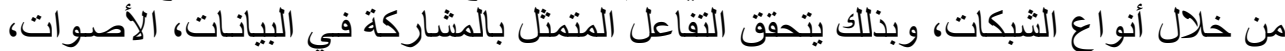

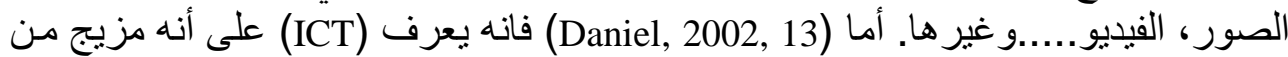

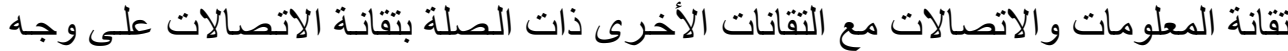

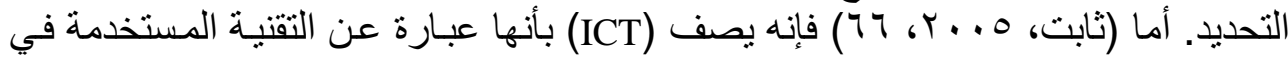


جمع البيانات من مصادر ها المختلفة بهدف الحصول على المعلومات من خلال استرجاءعاعها،

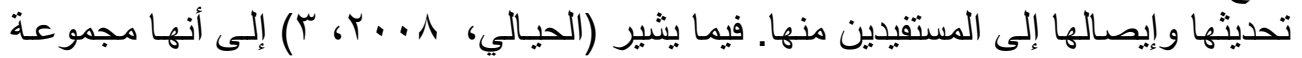

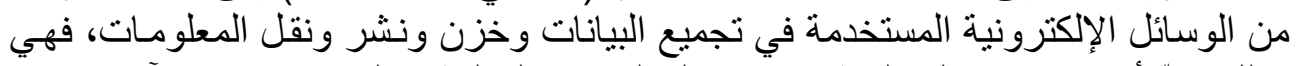

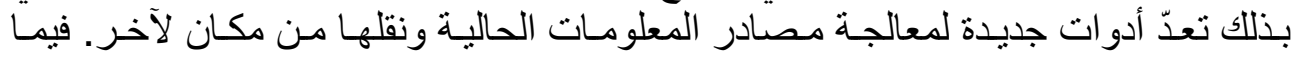

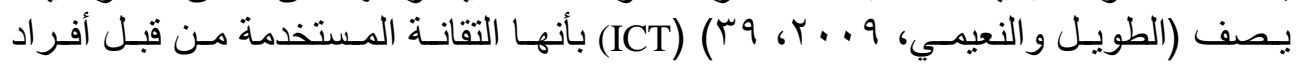

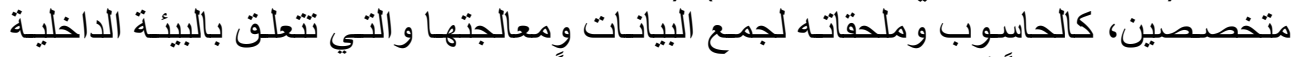

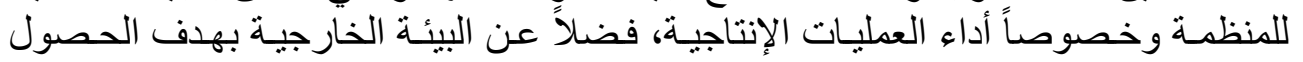

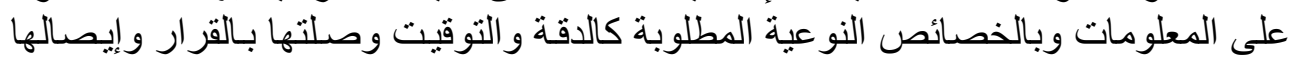

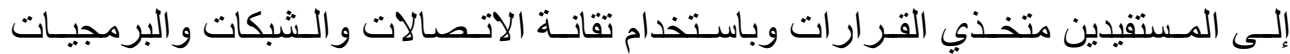

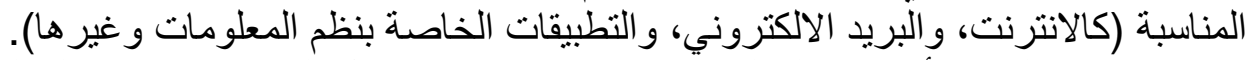

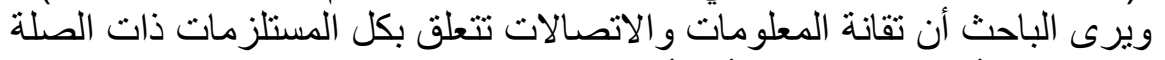

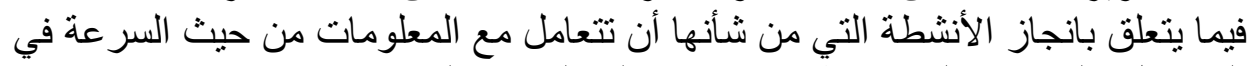
الحصول عليها وتعديلها وحفظظها وتوزيعها إلى الجهات التهات المستفيدة.

r. أهمية تقانة المعلومات والاتصالات

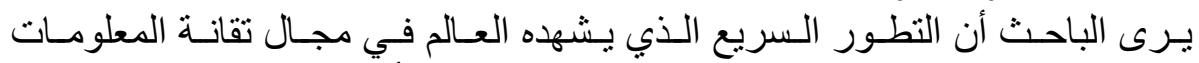

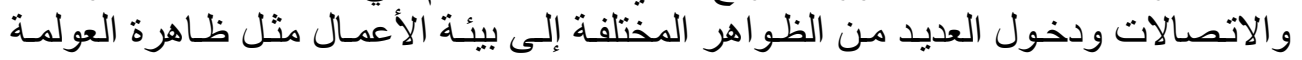

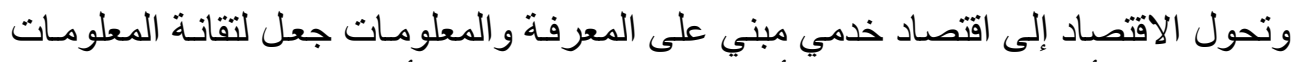

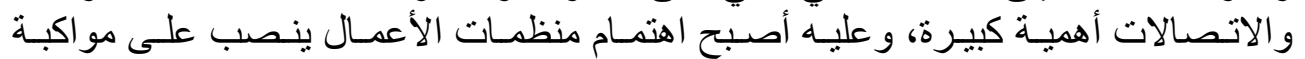

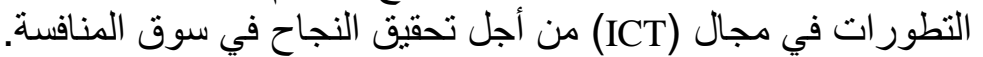

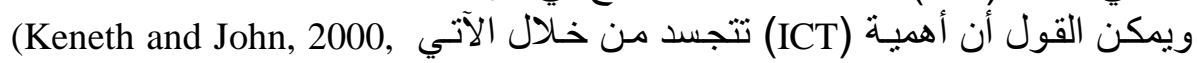
:(Haag and Lummings, 2006, 40) (Daft, 2001, 246) 119)

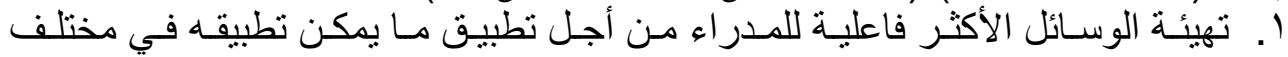

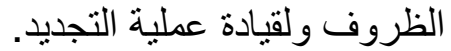

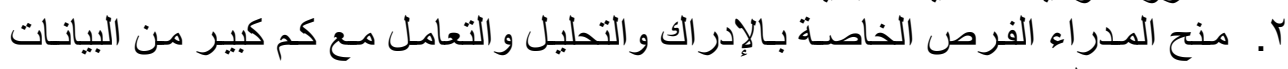
وصيغ معالجتها.

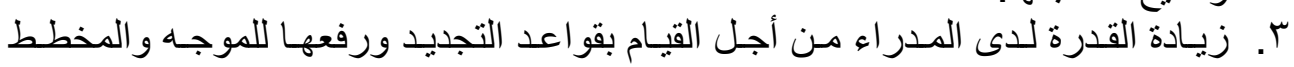
و والمستفيد بدقة وسر علة لادي.

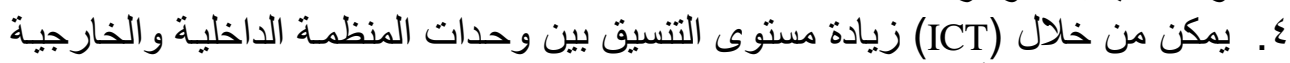

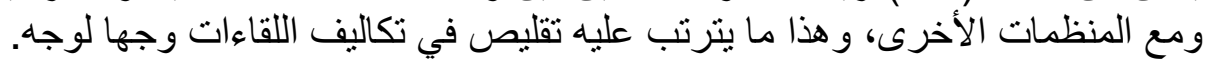

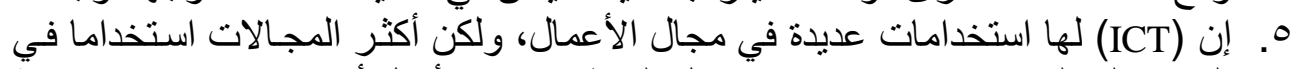

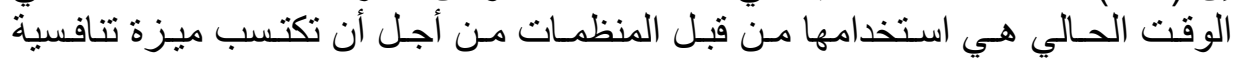

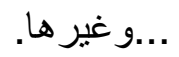

r. مكونات تقانة المعلومات والاتصالات

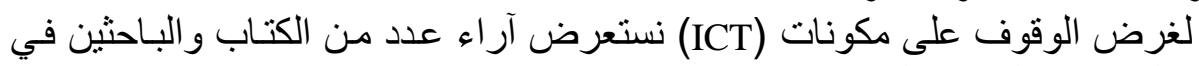

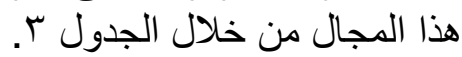




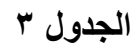

مكونات تقانة المعومات والاتصالات بحسب آراء مجموعة من الكتاب والباحثين

\begin{tabular}{|c|c|c|c|c|c|c|}
\hline المعلومات & التطبيقات & البشريةـــارد & والاتشبكات & البرامجيات & والمعداتــزة & \\
\hline & & & $\sqrt{ }$ & $\sqrt{ }$ & $\sqrt{ }$ & Cleary,1998 \\
\hline & & & $\sqrt{ }$ & $\sqrt{ }$ & $\sqrt{ }$ & Alter,1999 \\
\hline & & $\sqrt{ }$ & $\sqrt{ }$ & & $\sqrt{ }$ & ألسالمي، .... \\
\hline & $\sqrt{ }$ & $\sqrt{ }$ & $\sqrt{ }$ & $\sqrt{ }$ & $\sqrt{ }$ & Nickerson,2001 \\
\hline$\sqrt{ }$ & & & $\sqrt{ }$ & $\sqrt{ }$ & $\sqrt{ }$ & $\mathrm{Oz}, 2002$ \\
\hline$\sqrt{ }$ & $\sqrt{ }$ & & $\sqrt{ }$ & $\sqrt{ }$ & $\sqrt{ }$ & Turban,2002 \\
\hline & $\sqrt{ }$ & $\sqrt{ }$ & $\sqrt{ }$ & $\sqrt{ }$ & $\sqrt{ }$ & OBrien,2003 \\
\hline & & $\sqrt{ }$ & $\sqrt{ }$ & $\sqrt{ }$ & $\sqrt{ }$ & Stair,2003 \\
\hline & $\sqrt{ }$ & & $\sqrt{ }$ & $\sqrt{ }$ & $\sqrt{ }$ & 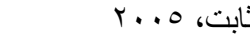 \\
\hline$\sqrt{ }$ & $\sqrt{ }$ & & $\sqrt{ }$ & $\sqrt{ }$ & $\sqrt{ }$ & $\begin{array}{cc}\text { Backer } & \text { CPA } \\
\text { Review } & 2005 \\
\end{array}$ \\
\hline
\end{tabular}

المصدر: من إعداد الباحث

ووفقاً للجدول أعلاه، فقد تم اعتماد المكونات الآتية (الأجزةة والمعدات، البرامجيات،

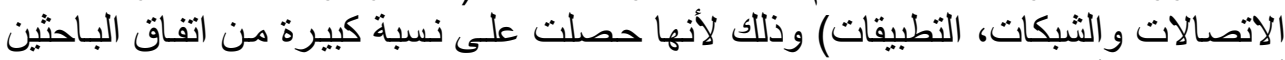

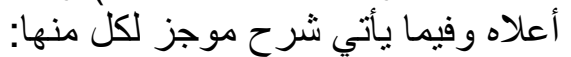

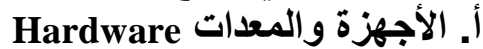

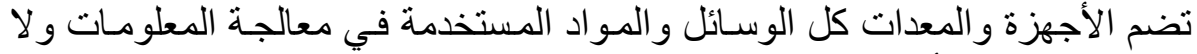

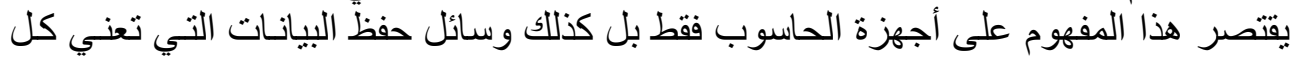

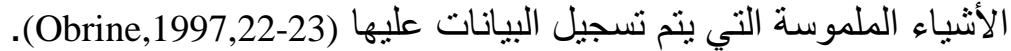

ويمكن تقسيم الأجهزة و المعدات إلى (Haag et al, 2007, 15):

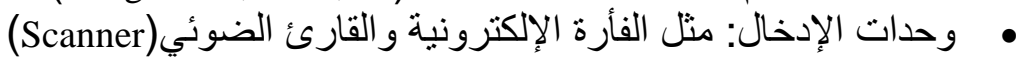

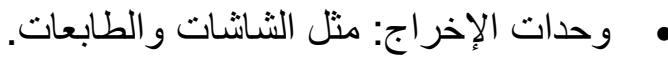

• • وحدات الخزن: مثل الأقر اص المثغنطة وتقنية الـ (Flash Memory)

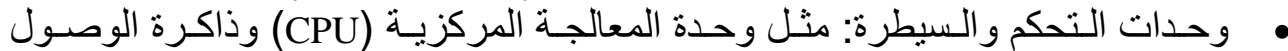

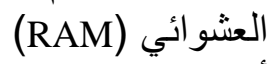

(Satellite), (Modem) •

(Cord), (Ports) • • • • •

ب. بالبرامجيات Software

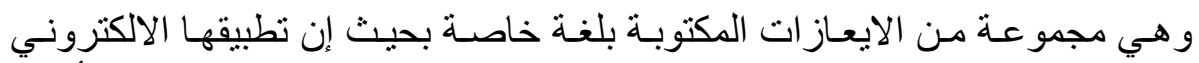

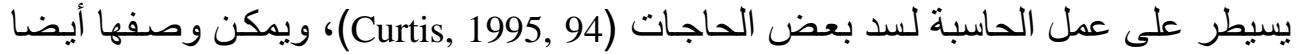

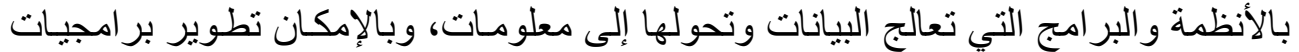

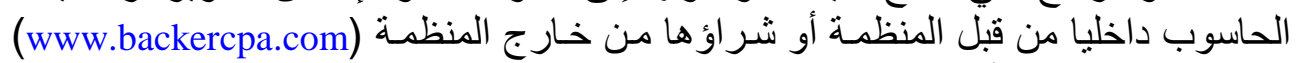

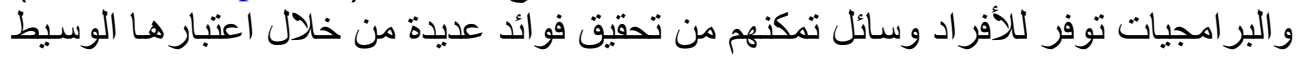
بين المستفيد والمعلومات المخزنة في الحاسوب (Laudon and Laudon, 2000, 195). 


\section{ج الاتصالات والشبكات Networks and Communication}

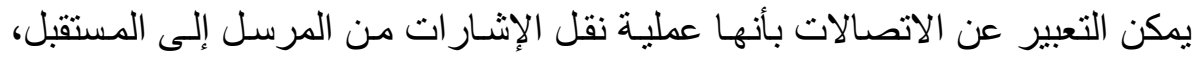

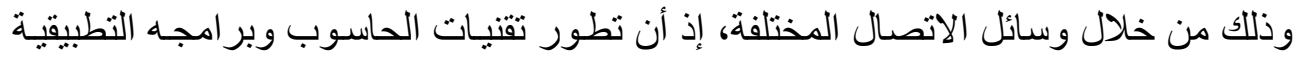

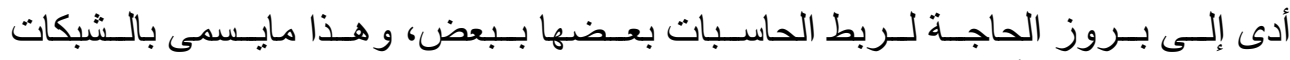

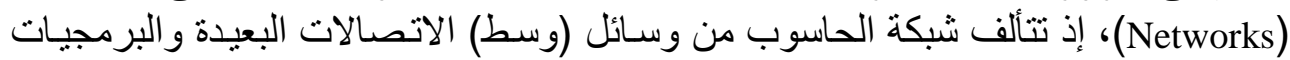

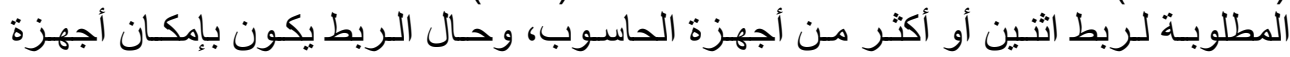

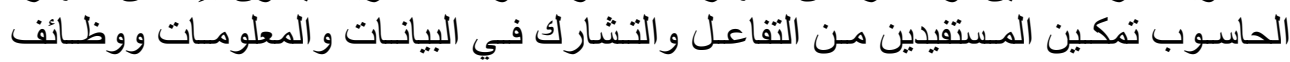

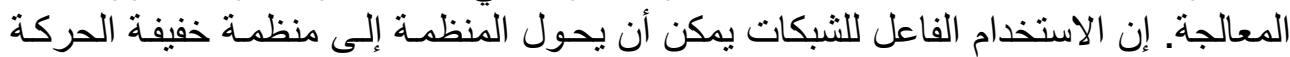

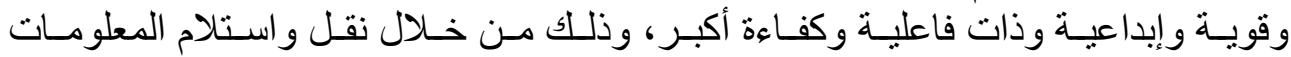

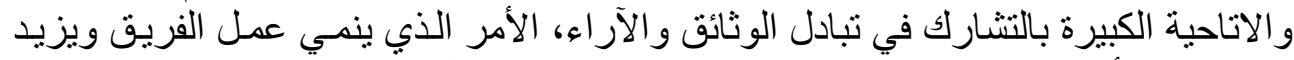

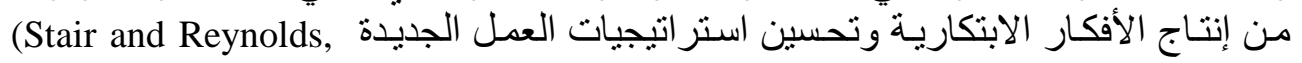
.2003, 226-229)

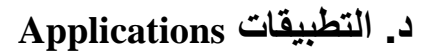

و هي التي تمكن المستفيدين من حل المشـاكل الخاصـة التـي قد تظهر في المنظمـة،

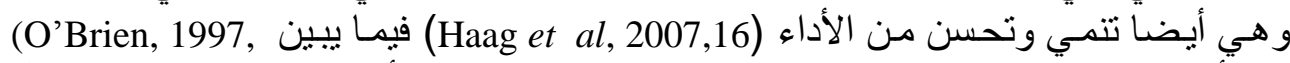

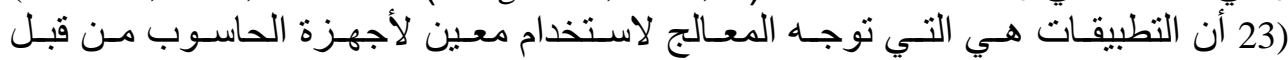

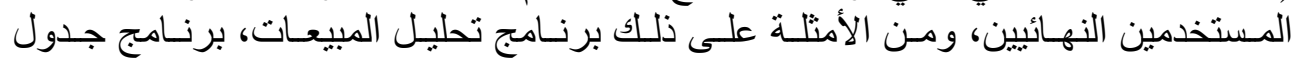

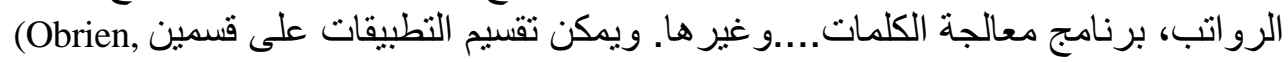

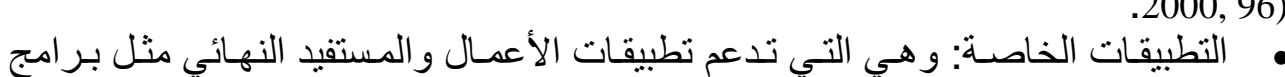

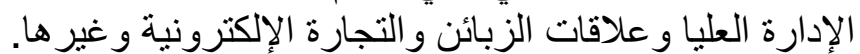

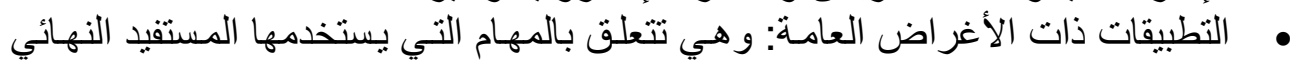

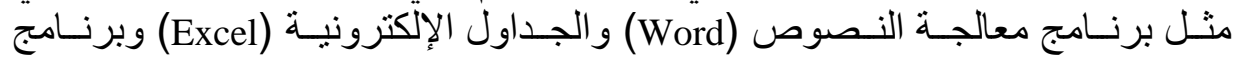
العرض (Power Point) وبر امج نظام إدارة قو اعد البيانات Data Base Management)

system)

Personal Entrepreneurs ثنانياً- الريادة الشخصية

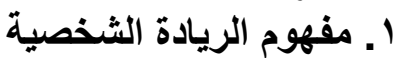

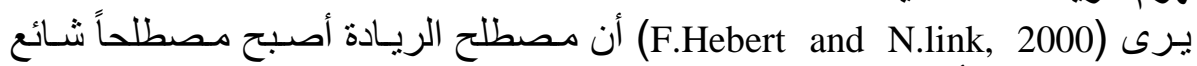

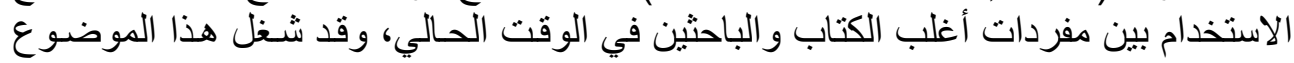

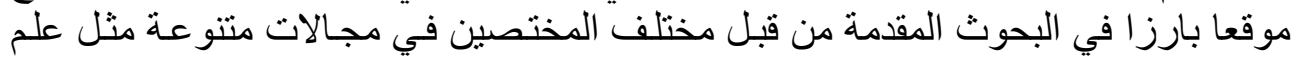

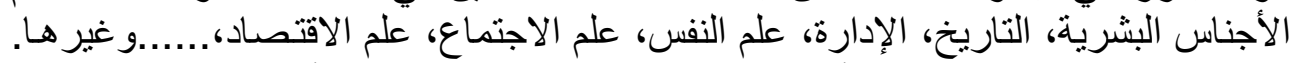

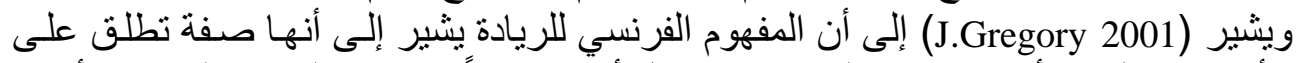

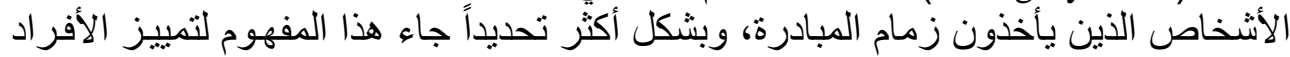

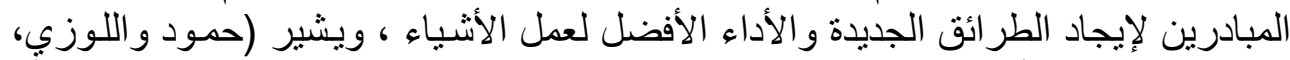

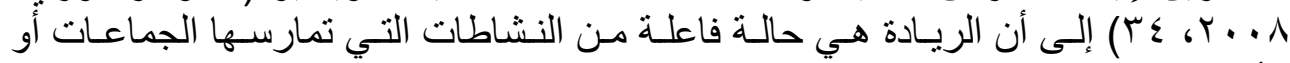

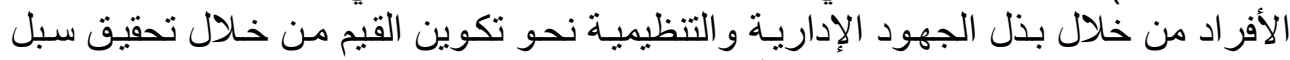

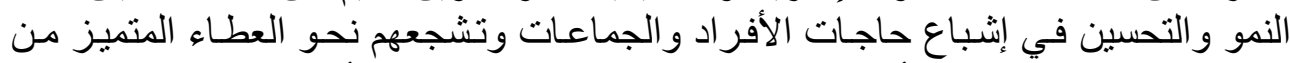

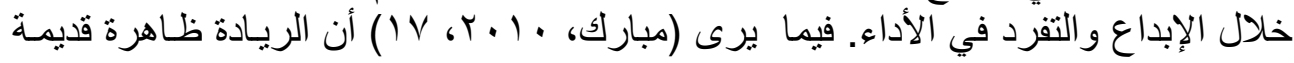


حديثة متجددة تحمل في طياتها معاني ورموز خيرة، فمنذ فجر التاريخ وهي تستخدم للالالاتة

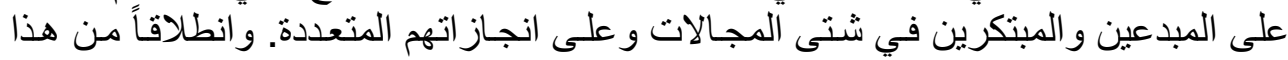

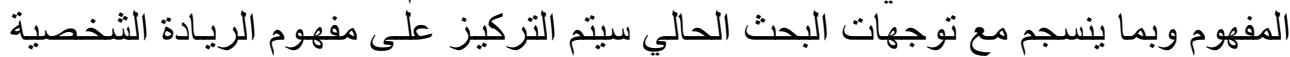

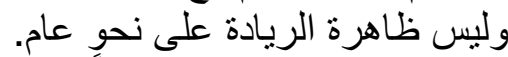

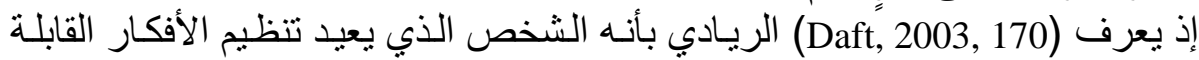

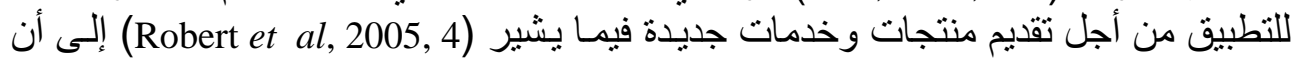

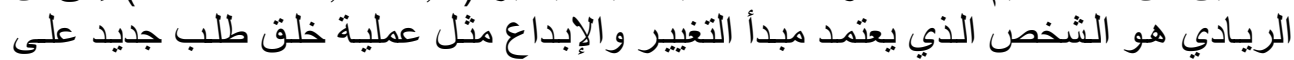

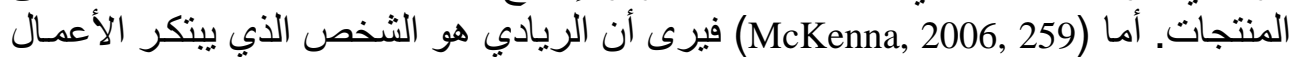

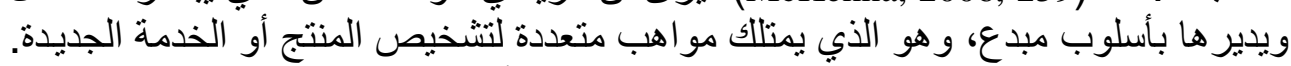

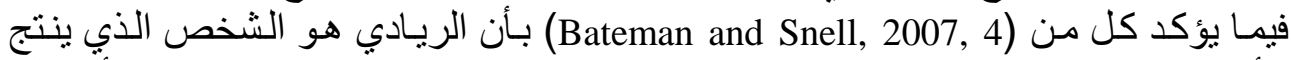

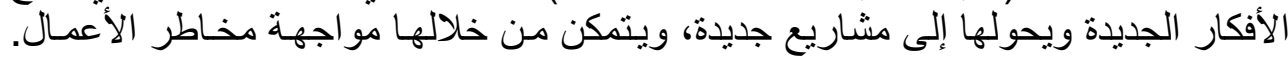

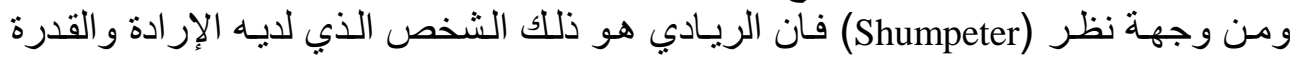

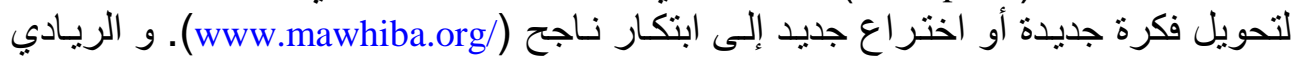

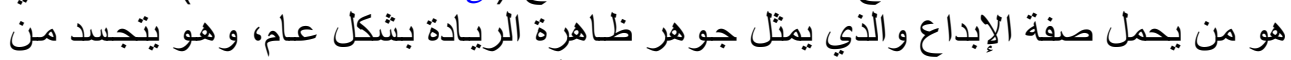

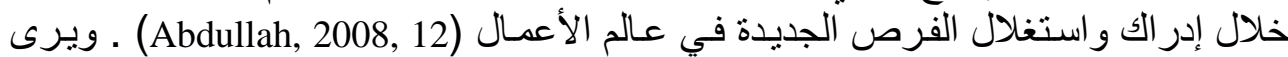

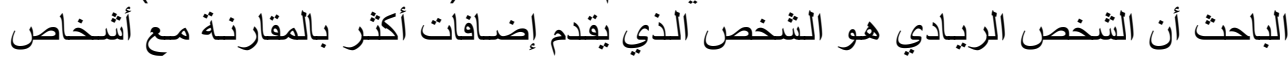

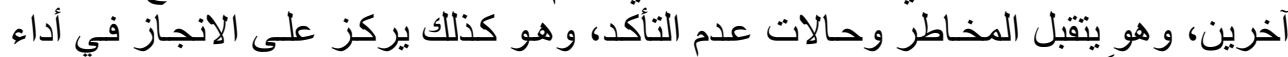
المهام، فضلاً عن تسخير الوقت والجهر وحالت والمال من أجل تحقيق الأداء الريادي.

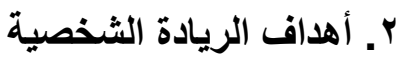

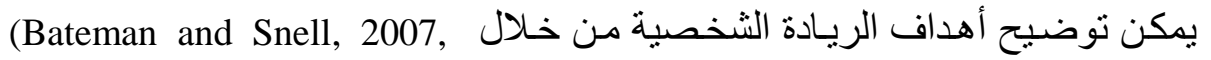

:(J.Gregory 2001)،(Abass, 2009, 41)،(Daft, 2003, 170) ، (226) • مكين الفرد من الاستقلالية في العمل وتعظيم القدرة على مواجهة التحديات و الشعور

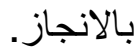
ابتكار وتطبيق وتقدبم الجديد من الأفكار و المنتجات و الخدمات.

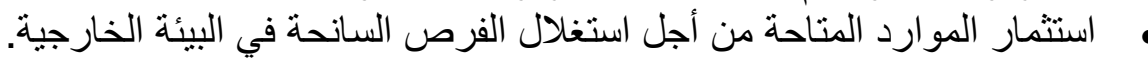

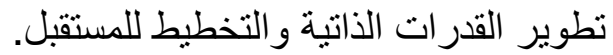

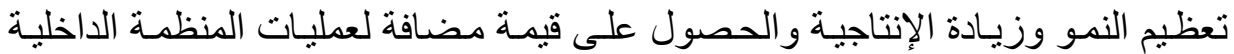

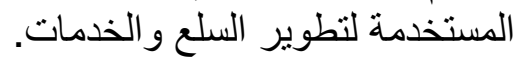

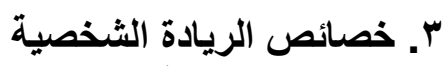

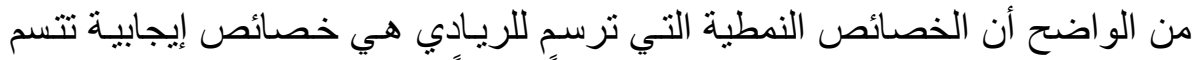

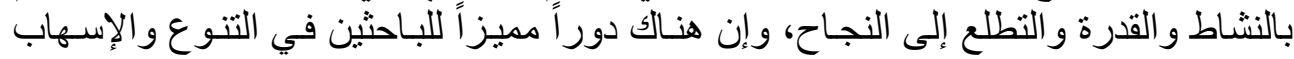

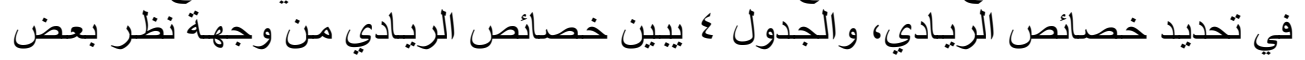
و الباحثنين: - n فيد 


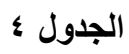

خصائص الريادة الثخصية حسب آراء مجموعة من الكتاب والباحثين

\begin{tabular}{|c|c|c|c|c|c|c|c|}
\hline المعرفة & المرونة & الرؤية & الفرصغلال & المخاطل & المبادرة & الإبداع & \\
\hline & & $\sqrt{ }$ & $\sqrt{ }$ & & $\sqrt{ }$ & $\sqrt{ }$ & $\begin{array}{c}\text { Mishra2002 } \\
\text { (www.ruddfoundation. } \\
\text { org) }\end{array}$ \\
\hline & $\sqrt{ }$ & & $\sqrt{ }$ & $\sqrt{ }$ & & & Daft, 2003 \\
\hline & & $\sqrt{ }$ & $\sqrt{ }$ & & $\sqrt{ }$ & $\sqrt{ }$ & Robert and et.al,2005 \\
\hline & & $\sqrt{ }$ & $\sqrt{ }$ & $\sqrt{ }$ & & $\sqrt{ }$ & Mckenna,2006 \\
\hline & & $\sqrt{ }$ & $\sqrt{ }$ & & & $\sqrt{ }$ & Abdullah,2008 \\
\hline & & & $\sqrt{ }$ & $\sqrt{ }$ & & $\sqrt{ }$ & Abass,2009 \\
\hline$\sqrt{ }$ & $\sqrt{ }$ & & & & $\sqrt{ }$ & $\sqrt{ }$ & $\begin{array}{c}\text { Goldsmith } \\
\text { (www.web.extension.u } \\
\text { iuc.edu/) }\end{array}$ \\
\hline
\end{tabular}

المصدر: من إعداد الباحث

وفي سياق البحث الحالي وبما ينسجم مع متغيرات البحث المستقلة فإنها سيتم اعتمـاد

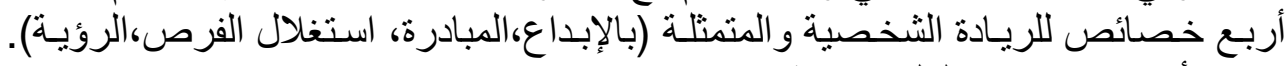
وفيما يأتي شرح موجز لكل خاصية:

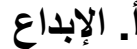

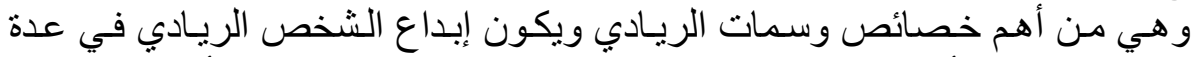

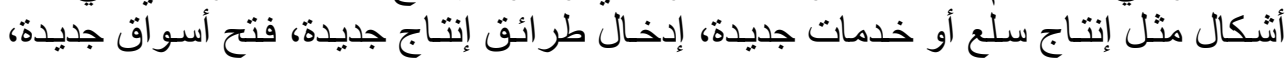
إيجاد مصادر تمويل بديلة، وصف طريقة تنظيميـة جديدة،......و غير هـا (www.umbb.dz)

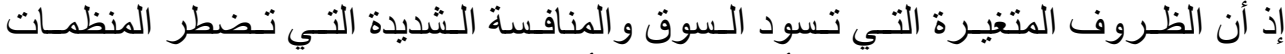

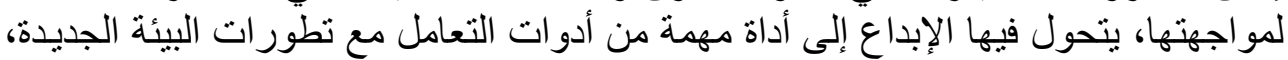

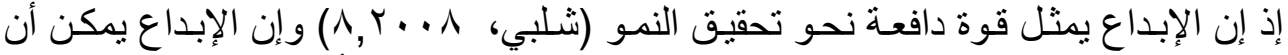
يعطي قيمة جديدة للشخص الريـادي وكذلك قيمة جديدة للمنتجـات أو الخدمات التهات التي يقدمها

.(Robert et al 2005, 20)

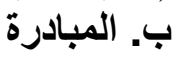

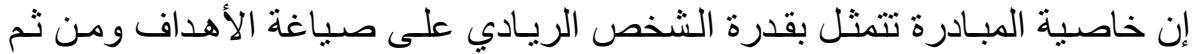

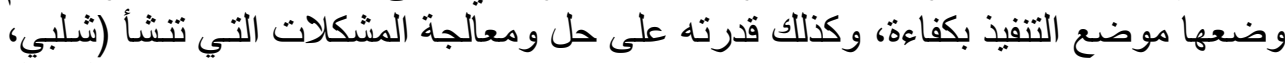

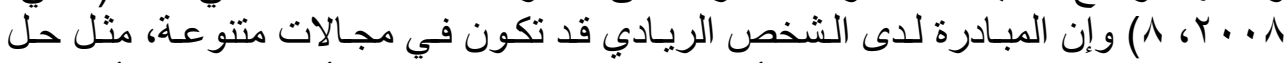

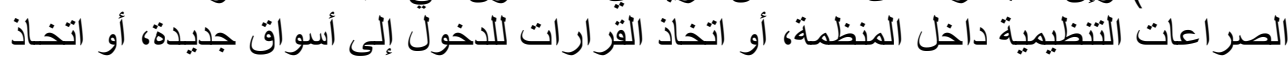

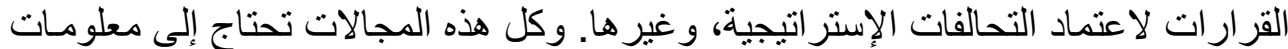

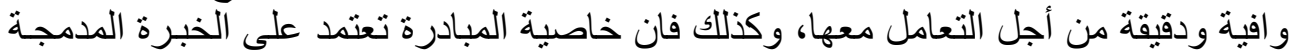

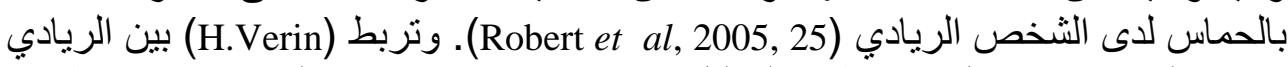

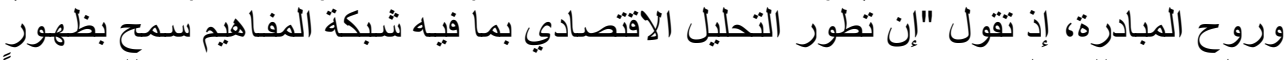

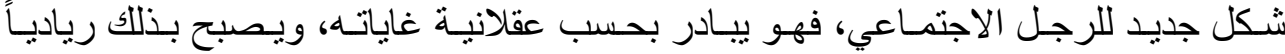

(www.umbb.dz)

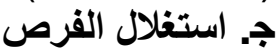

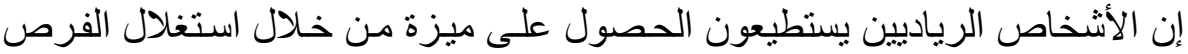

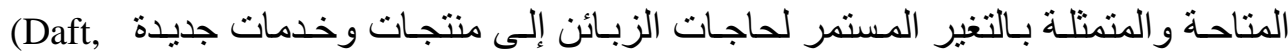




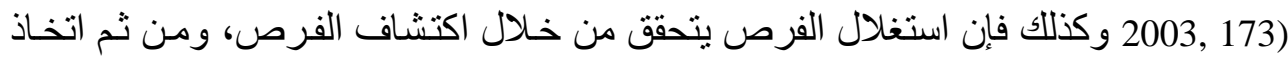

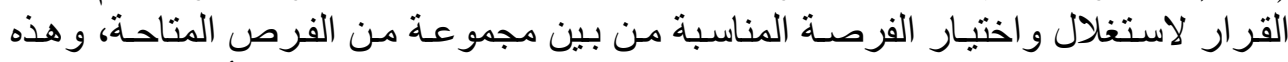

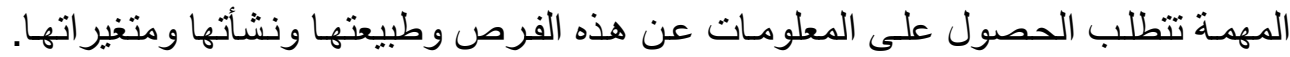

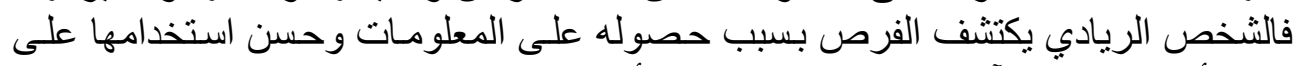

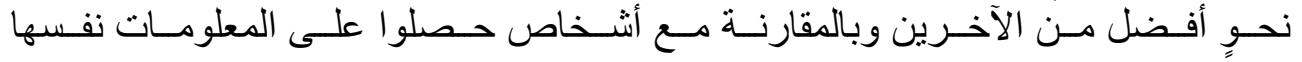
(www.sustainablevaluepartners.com) د. الروية

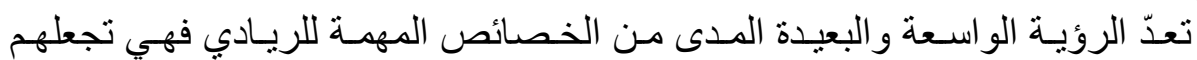

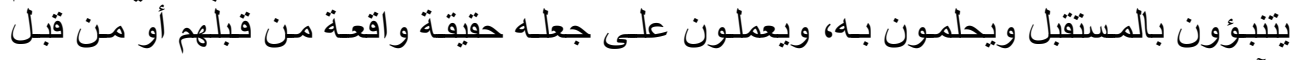

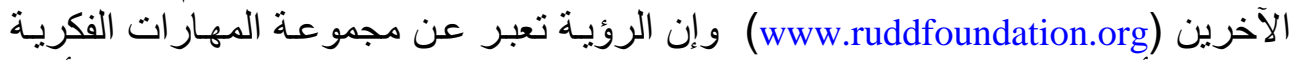

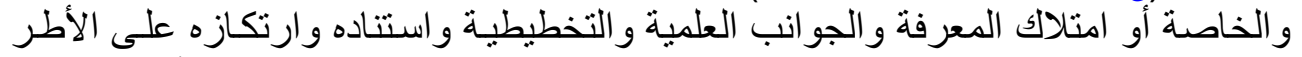

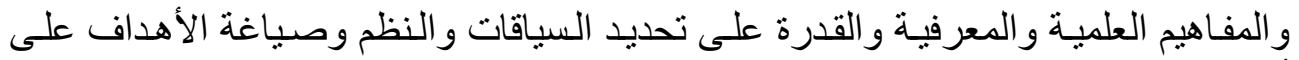
أسس الرشد و العقلانية (www.umbb.dz).

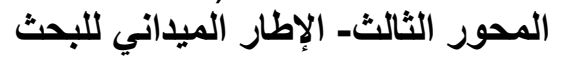

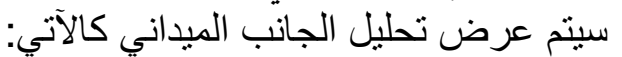

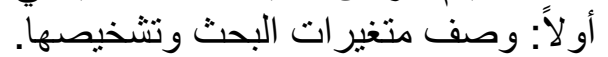
ثنانياً: اختبار فرضيات البحث.

أولاًا وصف متغيرات البحث وتثخيصها ا ـ وصف متغيرات تقانة المعلومات واتفيرات والاتصالات وتثخيصها

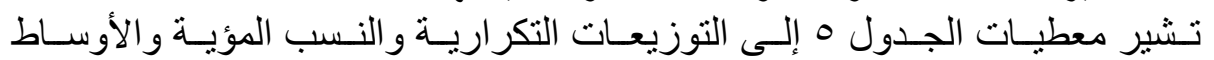

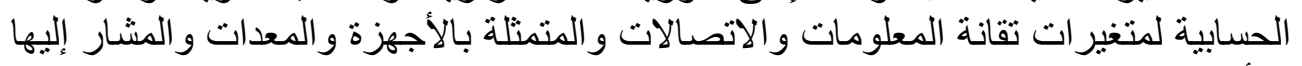

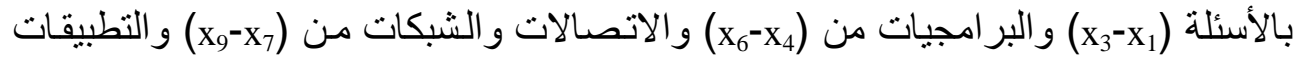
من $\left(x_{12}-x_{10}\right)$ 


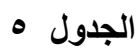

التوزيعات التكرارية والوسط الحسابي والانحراف المعياري لتقانة المعلومات والاتصالات

\begin{tabular}{|c|c|c|c|c|c|c|c|c|c|c|c|c|}
\hline \multirow{2}{*}{ المبحيزئي } & \multirow{2}{*}{ الصنبي } & \multicolumn{10}{|c|}{ 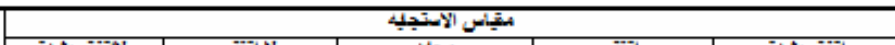 } & \multirow[b]{2}{*}{$=$} \\
\hline & & \multicolumn{2}{|c|}{ لأمتق بشدة } & \multicolumn{2}{|c|}{ لy } & \multicolumn{2}{|c|}{ मे } & \multicolumn{2}{|c|}{ of } & \multicolumn{2}{|c|}{ 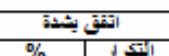 } & \\
\hline 1.05 & 3.98 & 5.0 & 2 & 7.5 & 3 & 2.50 & 1 & 55.0 & 22 & 30.0 & 12 & $\mathrm{X}_{1}$ \\
\hline 0.94 & 3.98 & - & - & 7.5 & 3 & 22.50 & 9 & 35.0 & 14 & 35.0 & 14 & $\mathbf{X}_{2}$ \\
\hline 1.00 & 3.36 & 2.5 & 1 & 10.0 & 4 & 30.0 & 12 & 37.5 & 15 & 20.0 & 8 & $\mathrm{X}_{3}$ \\
\hline 0.99 & 3.77 & \multicolumn{2}{|c|}{2.5} & \multicolumn{2}{|c|}{8.3} & \multicolumn{2}{|c|}{18.0} & \multicolumn{2}{|c|}{42.5} & \multicolumn{2}{|c|}{28.3} & المهزئر الككي \\
\hline 1.03 & 3.45 & 2.5 & 1 & 17.5 & 7 & 27.5 & 11 & 37.5 & 15 & 15.0 & 6 & $\mathrm{X}_{4}$ \\
\hline 1.01 & 3.58 & 2.5 & 1 & 12.5 & 5 & 27.5 & 11 & 40.0 & 16 & 17.5 & 7 & $X_{5}$ \\
\hline 1.08 & 3.45 & 2.5 & 1 & 20.0 & 8 & 25.0 & 10 & 35.0 & 14 & 17.5 & 7 & $\mathrm{X}_{6}$ \\
\hline 1.04 & 3.49 & \multicolumn{2}{|c|}{2.5} & & & \multicolumn{2}{|c|}{26.6} & \multicolumn{2}{|c|}{37.5} & \multicolumn{2}{|c|}{16.6} & السموشر الككئي \\
\hline 0.94 & 3.33 & - & - & 20.0 & 8 & 40.0 & 16 & 27.5 & 11 & 12.5 & 5 & $\mathrm{X}_{7}$ \\
\hline 0.95 & 3.43 & 5.0 & 2 & 10.0 & 4 & 30.0 & 12 & 47.5 & 19 & 7.5 & 3 & $\mathbf{X}_{8}$ \\
\hline 0.95 & 3.45 & 2.5 & 1 & 15.0 & 6 & 27.5 & 11 & 45.0 & 18 & 10.0 & 4 & $\mathrm{X}_{9}$ \\
\hline 0.94 & 3.40 & \multicolumn{2}{|c|}{2.5} & \multicolumn{2}{|c|}{15.0} & \multicolumn{2}{|c|}{32.5} & \multicolumn{2}{|c|}{40.0} & \multicolumn{2}{|c|}{10.0} & أكنونش الكلي \\
\hline 1.03 & 3.50 & - & - & 25.0 & 10 & 15.0 & 6 & 45.0 & 18 & 15.0 & 6 & $\mathrm{X}_{10}$ \\
\hline 1.08 & 3.40 & 2.5 & 1 & 20.0 & 8 & 30.0 & 12 & 30.0 & 12 & 17.5 & 7 & $\mathrm{X}_{11}$ \\
\hline 0.94 & 3.23 & 2.5 & 1 & 22.5 & 9 & 30.0 & 12 & 40.0 & 16 & 5.0 & 2 & $\mathrm{X}_{12}$ \\
\hline 1.01 & 3.37 & \multicolumn{2}{|c|}{1.6} & & & \multicolumn{2}{|c|}{25.0} & & & \multicolumn{2}{|c|}{12.5} & أسنوش اكليّي \\
\hline
\end{tabular}

أ. الأجهزة والمعدات: نثير النسب المئوية في الجدول ه إلى أن (70.8\%) من المبحوثين

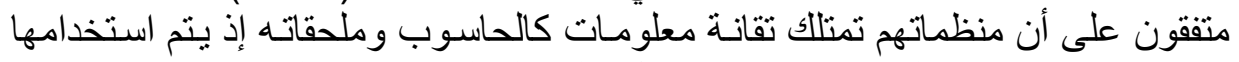

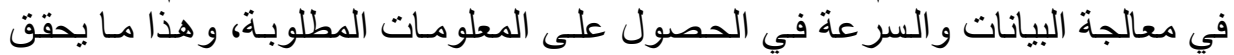

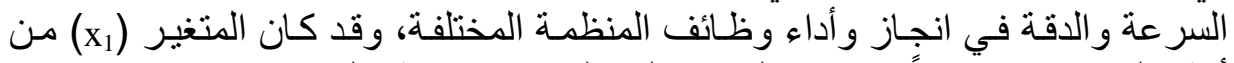

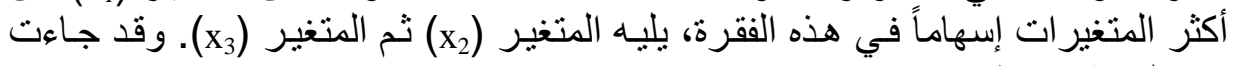

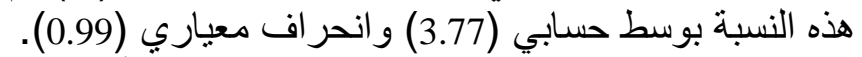

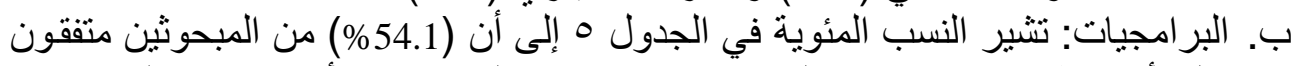

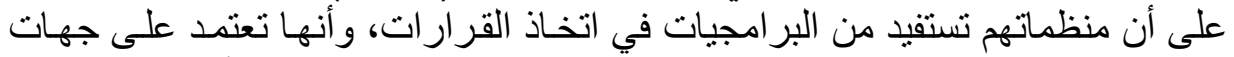

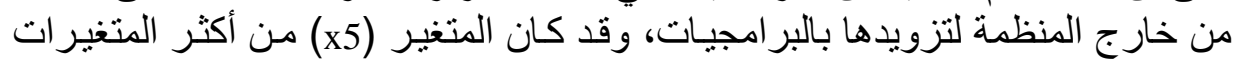

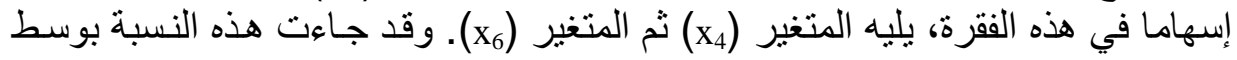
حسابي (3.49) و انحر اف معياري (1.04). ت. الاتصالات والثبكات: تشير النسب المؤية في الجدول ه إنى إلى أن (50\%) من المبحوثين

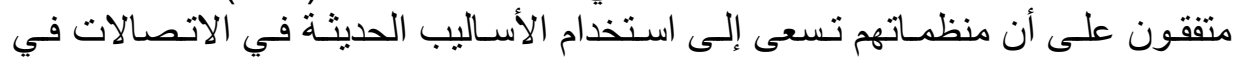

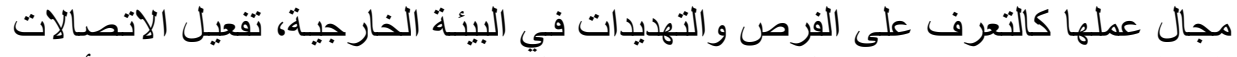

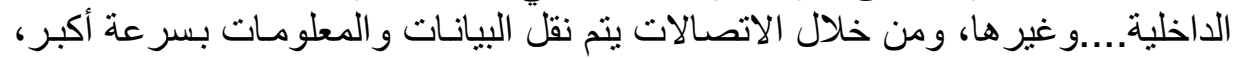

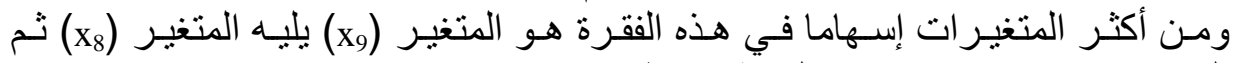
المتغير (x) ث. التطبيقات: تشير النسب المؤيسة في الجدول ه إلى أن (50.8\%) من المبحوثين متفقون

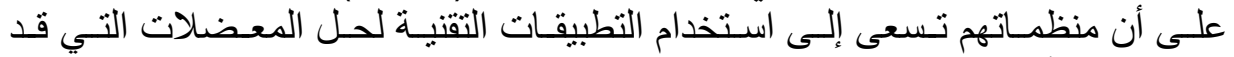

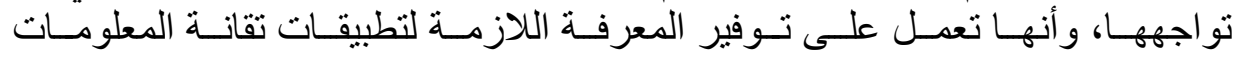
والاتصالات، ومن أكثر المتغيرات إسهاما في هذه الفقرة هو المتغير (x10) يليه المتغير 


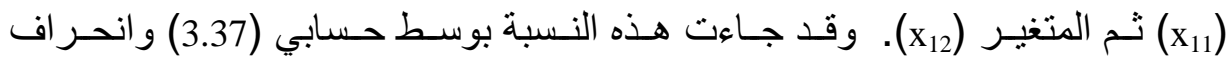

$$
\text { معياري (1.01). }
$$

r ـ وصف متغيرات الريادة الثخصية وتثخيصها

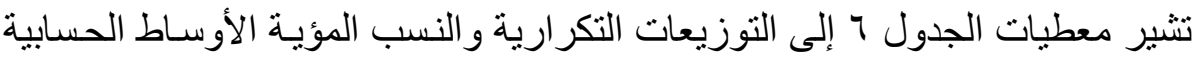

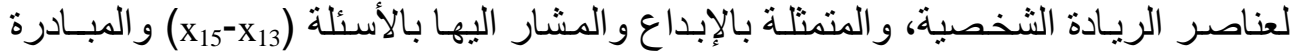
من

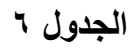

التوزيعات التكرارية والوسط الحسابي والانحراف المعياري للريادة الثخصية

\begin{tabular}{|c|c|c|c|c|c|c|c|c|c|c|c|c|}
\hline \multirow{3}{*}{ المعيأريات } & \multirow{3}{*}{ الحستيط } & \multirow{2}{*}{\multicolumn{10}{|c|}{ 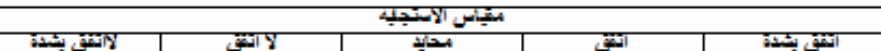 }} & \multirow{3}{*}{$=$} \\
\hline & & & & \multicolumn{2}{|c|}{ 正 } & \multicolumn{2}{|c|}{ نحيثي } & \multicolumn{2}{|c|}{ آتصن } & \multicolumn{2}{|c|}{ 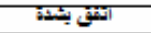 } & \\
\hline & & $\%$ & إلىرز & $\%$ & إلىرز & $\%$ & إليكرJ & $\%$ & اليكرز & $\%$ & إليكرJ & \\
\hline 1.15 & 3.60 & 2.5 & 1 & 20.0 & 8 & 17.5 & 7 & 35.0 & 14 & 25.0 & 10 & $\mathrm{X} 13$ \\
\hline 0.90 & 3.60 & - & - & 15.0 & 6 & 22.5 & 9 & 50.0 & 20 & 12.5 & 5 & $\mathrm{Xl4}$ \\
\hline 0.93 & 3.55 & - & - & 15.0 & 6 & 30.0 & 12 & 40.0 & 16 & 15.0 & 6 & $\mathrm{X} 15$ \\
\hline 0.99 & 3.58 & \multicolumn{2}{|c|}{0.8} & \multicolumn{2}{|c|}{16.6} & \multicolumn{2}{|c|}{23.3} & \multicolumn{2}{|c|}{41.6} & \multicolumn{2}{|c|}{17.5} & ألكوني \\
\hline 0.91 & 3.68 & - & - & 15.0 & 6 & 17.5 & 7 & 52.5 & 21 & 15.0 & 6 & X16 \\
\hline 6.29 & 4.65 & - & - & 15.0 & 6 & 22.5 & 9 & 40.0 & 16 & 20.0 & 8 & $\mathrm{Xl7}$ \\
\hline 0.92 & 3.65 & - & - & 15.0 & 6 & 20.0 & 8 & 50.0 & 20 & 15.0 & 6 & $\mathrm{X} 18$ \\
\hline 2.70 & 3.99 & & & \multicolumn{2}{|c|}{15.0} & \multicolumn{2}{|c|}{20.0} & \multicolumn{2}{|c|}{47.5} & \multicolumn{2}{|c|}{16.6} & الكولي \\
\hline 0.91 & 3.82 & - & - & 7.5 & 3 & 27.5 & 11 & 37.5 & 15 & 25.0 & 10 & $\mathrm{X} 19$ \\
\hline 0.94 & 3.85 & - & - & 15.0 & 6 & 7.5 & 3 & 55.0 & 22 & 22.5 & 9 & $\mathbf{X} 20$ \\
\hline 0.89 & 3.75 & 2.5 & 1 & 15.0 & 6 & 20.0 & 8 & 45.0 & 18 & 17.5 & 7 & $\mathrm{X} 21$ \\
\hline 0.91 & 3.80 & & & 12.5 & & 18.3 & & 45.8 & & 21.6 & & 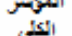 \\
\hline 0.89 & 3.75 & - & - & 12.5 & 5 & 17.5 & 7 & 52.5 & 21 & 17.5 & 7 & $\mathrm{X} 22$ \\
\hline 1.03 & 3.40 & 5.0 & 2 & 15.0 & 6 & 25.0 & 10 & 45.0 & 18 & 10.0 & 4 & $\mathrm{X} 23$ \\
\hline 1.08 & 3.58 & 2.5 & 1 & 17.5 & 7 & 20.0 & 8 & 40.0 & 16 & 20.0 & 8 & X24 \\
\hline 1.00 & 3.57 & & & & & & & & & & & الكئي \\
\hline
\end{tabular}

المصدر: من إعداد الباحث

أ. الإبداع: تشير النسب المؤية في الجدول 7 إلى أن (59.1\%) من المبحوثين متفقون

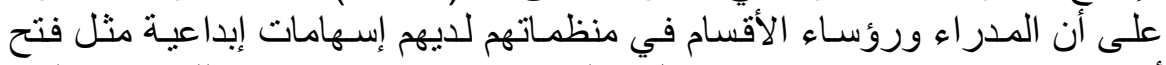

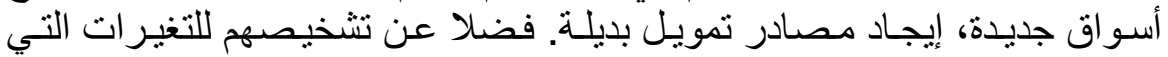

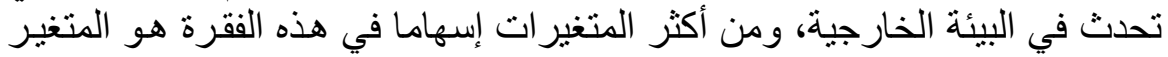

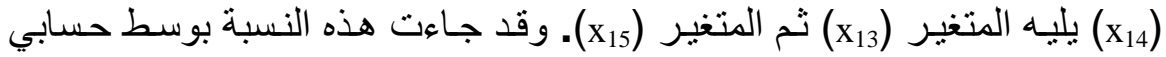

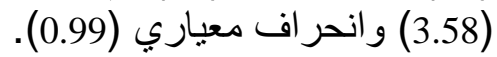

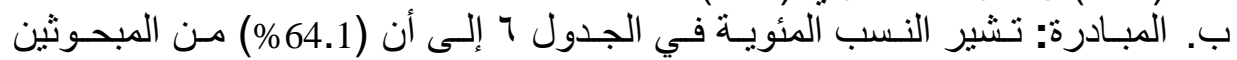

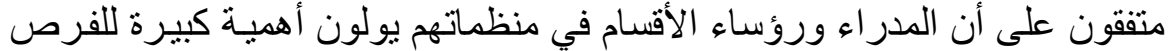

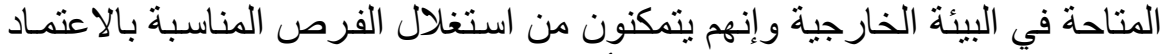

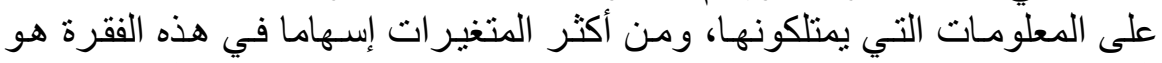

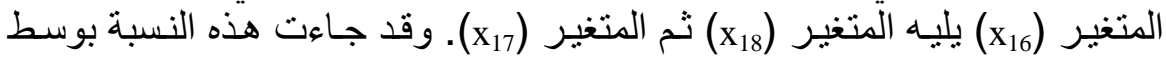
حسابي (3.99) و انحر اف معياري (2.70). 


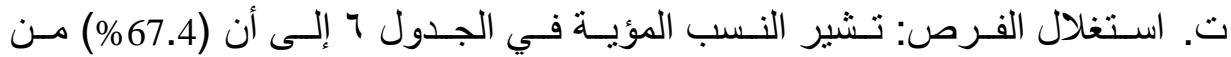

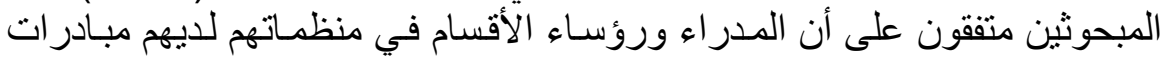

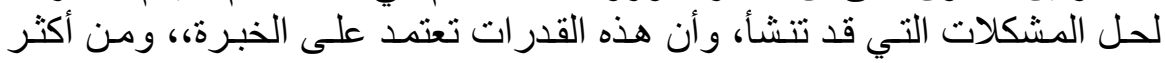

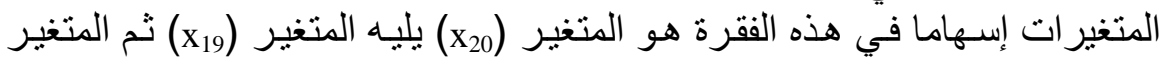
(x)

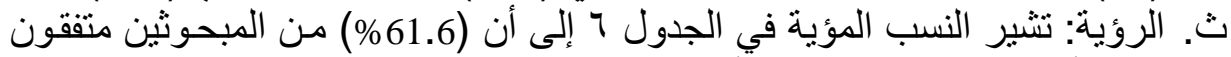

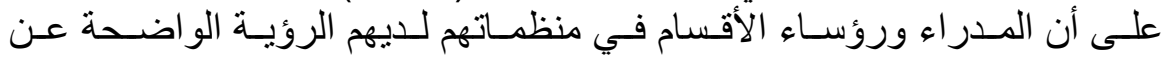

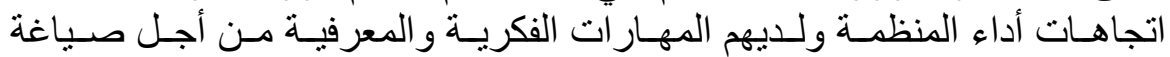

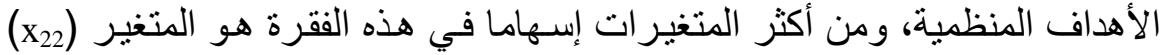

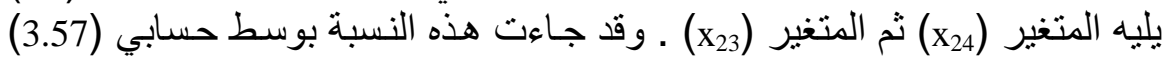
وانحر اف معياري (1.00).

\section{ثانياً اختبار فرضيات البحث}

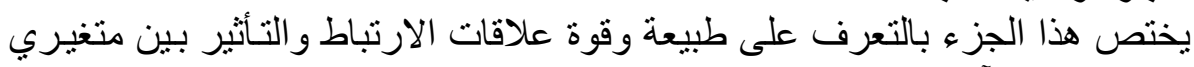

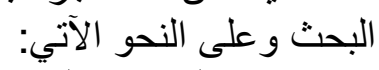

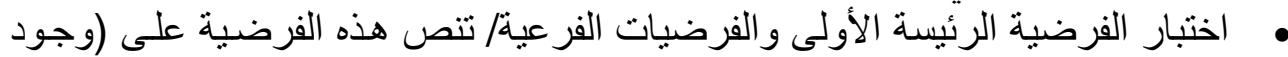

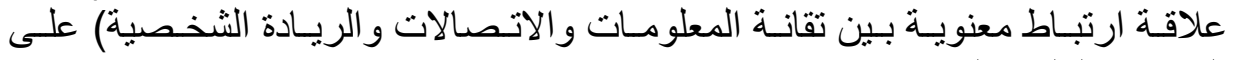
المسنوى الكلي و الجزئي.

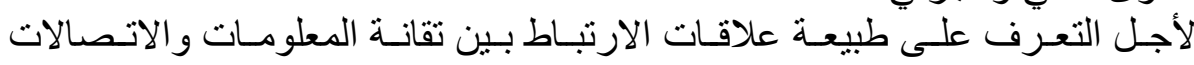

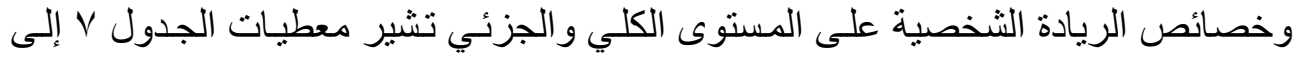

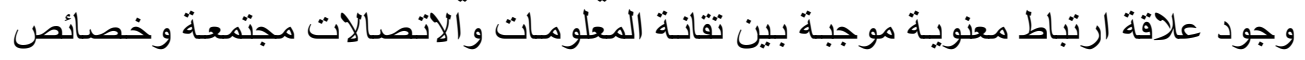

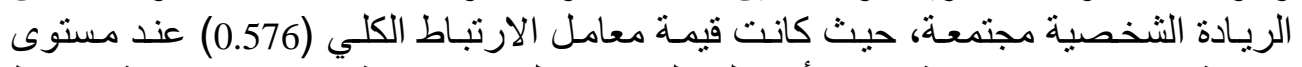

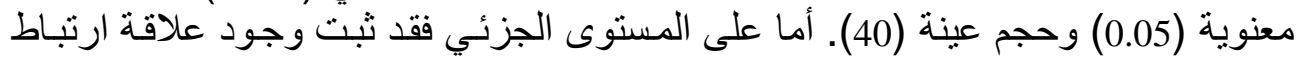

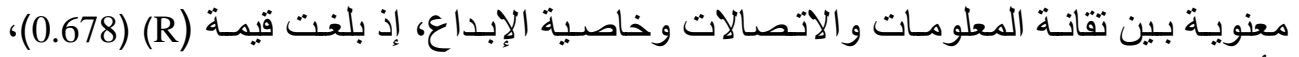

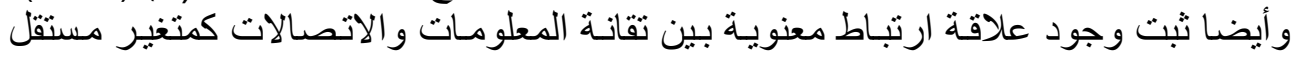

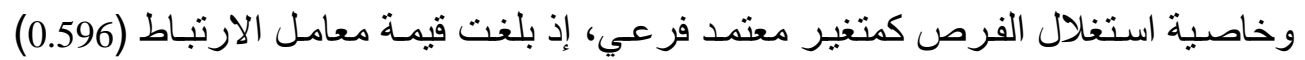

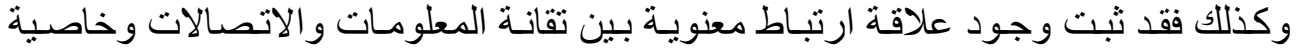

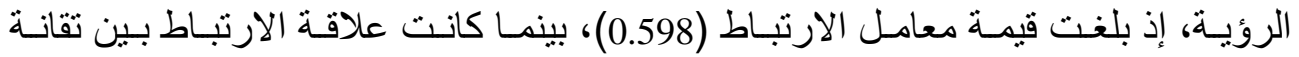

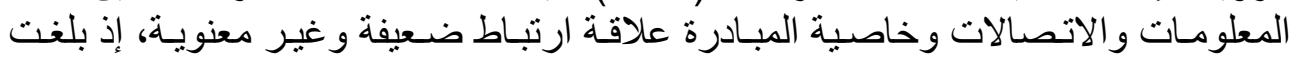

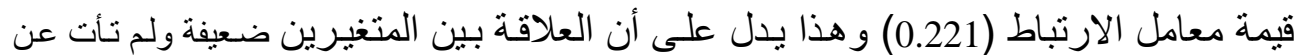

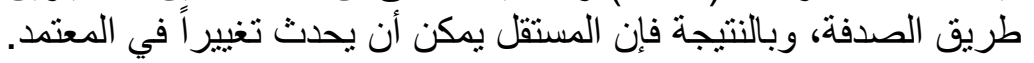

$$
\text { الجدول vل }
$$

\begin{tabular}{|c|c|c|c|c|c|}
\hline الكلي & الروية & استغلال الفرص & المبادرة & الإبداع & المتفير المستقل الخصائص \\
\hline $0.576^{*}$ & $0.598^{*}$ & $0.596^{*}$ & 0.221 & $0.679 *$ & تقانة المعلومات و الاتصالات \\
\hline \multicolumn{4}{|c|}{$\mathrm{N}=40$} & \multicolumn{2}{|c|}{ 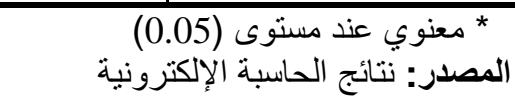 } \\
\hline
\end{tabular}

معامل الارتباط بين تقانة المعلومات و الاتصالات وخصائص الريادة الثخصية 
• اختبار الفرضية الرئيسة الثانية/ تنص هذه الفرضية على أنه (يوجد تأثنير معنوي لتقانـة

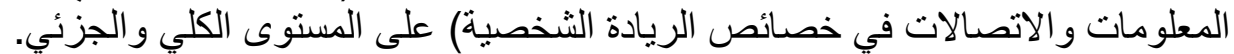

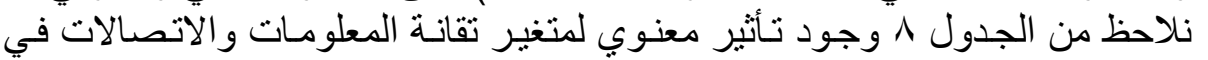

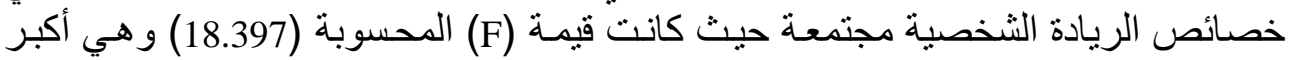

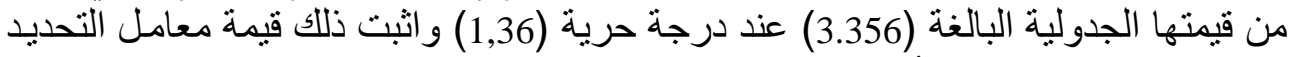
(R2)

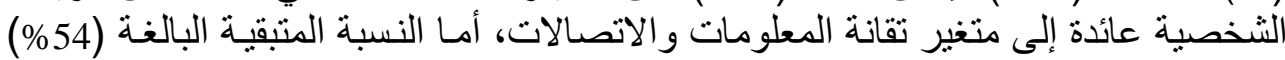
فتعود إلى متغير ات أخرى خارج إنغئ نطاق هذا البحث.

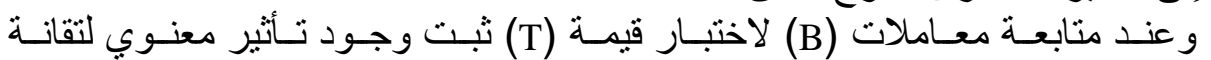

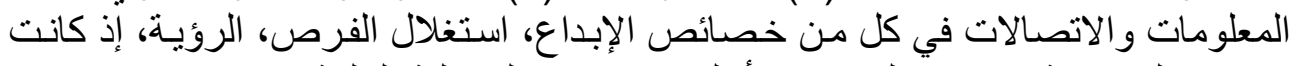

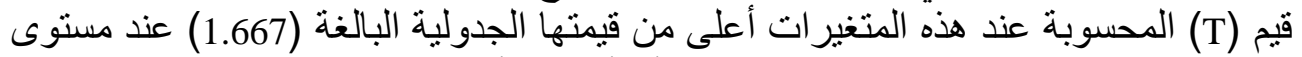

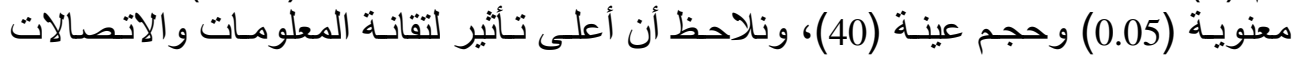

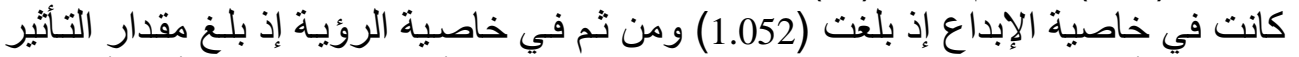

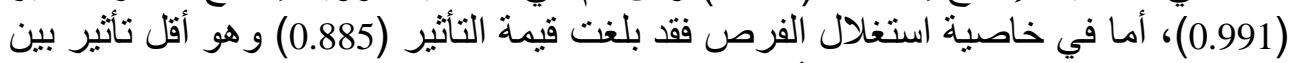

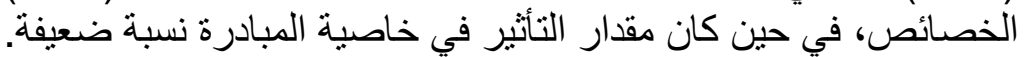

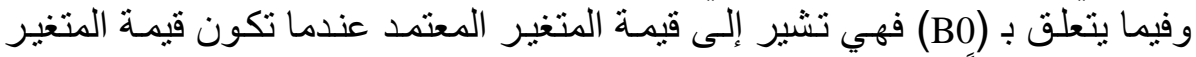

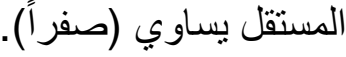

\begin{tabular}{|c|c|c|c|c|c|c|c|c|}
\hline \multicolumn{9}{|c|}{ ومات والاتص } \\
\hline \multicolumn{2}{|c|}{$\mathbf{F}$} & \multirow{2}{*}{$\mathbf{R}^{2}$} & \multicolumn{4}{|c|}{ خصائص الريادة الشخصية } & \multirow{2}{*}{$\beta_{0}$} & \multirow{2}{*}{ المعتمد } \\
\hline المجدولة & المحسوبة & & $\beta_{4}$ & $\beta_{3}$ & $\beta_{2}$ & $\beta_{1}$ & & \\
\hline \multirow[t]{2}{*}{3.356} & 18.397 & 0.460 & $\begin{array}{c}0.991 \\
(4.598)^{*}\end{array}$ & $\begin{array}{c}0.885 \\
(4.517)^{*}\end{array}$ & $\begin{array}{c}0.903 \\
(1.397)\end{array}$ & $\begin{array}{c}1.052 \\
(5.686)^{*}\end{array}$ & -1.260 & والاتصانة المعلومات \\
\hline & \multicolumn{2}{|c|}{$n=40$} & ${ }^{*}: \mathrm{p} \leq 0$. & & \multicolumn{4}{|c|}{ 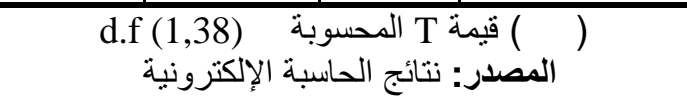 } \\
\hline
\end{tabular}

$$
\begin{aligned}
& \text { الاستنتاجات و التوصيات } \\
& \text { أولاًا الاستنتاجات }
\end{aligned}
$$

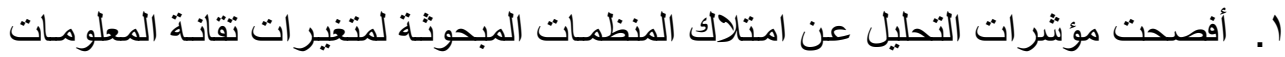

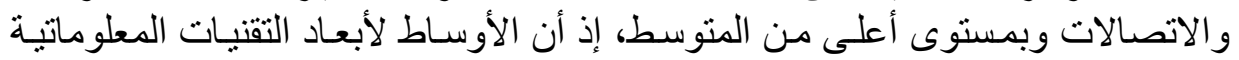
لاتقل عن باته

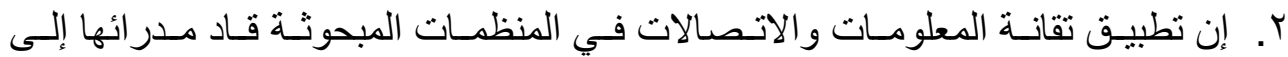

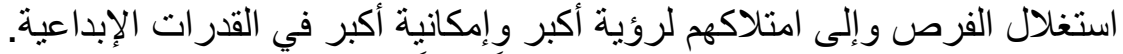

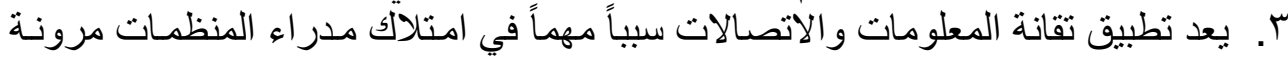
واضحة تجاه بيئة منظماتهم الخارجية.

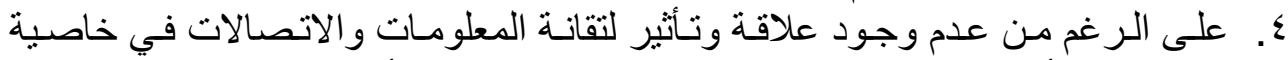

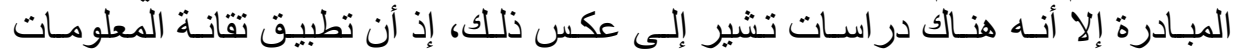
والاتصالات يمكن أن تؤدي إلى تحقيق خاصية المبادرة. 


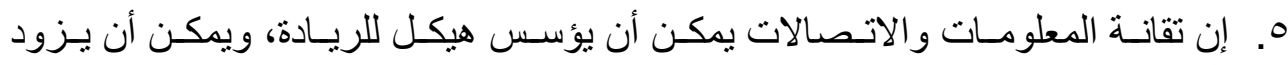
البصيرة للمدر اء لتحقيق النجاح و إيجاد الطر ائق الإبداعية.

ثانياً- التوصيات

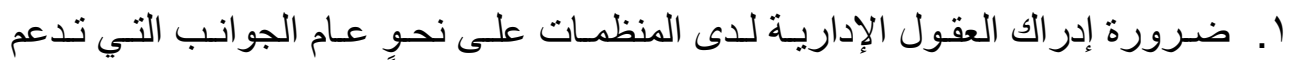

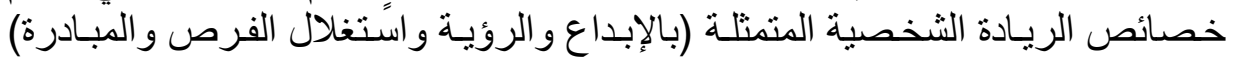

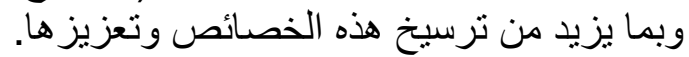

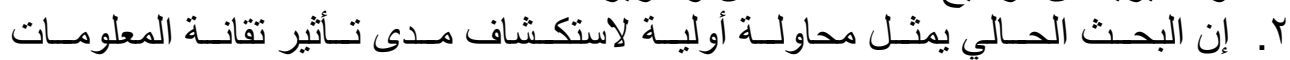

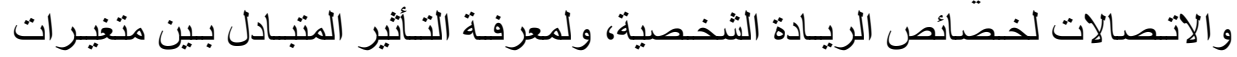

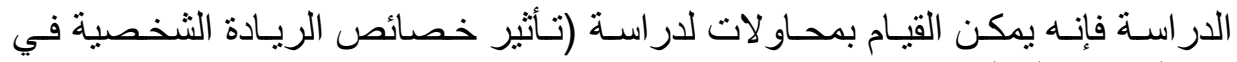

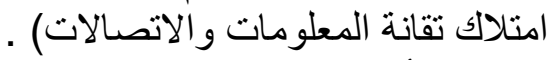

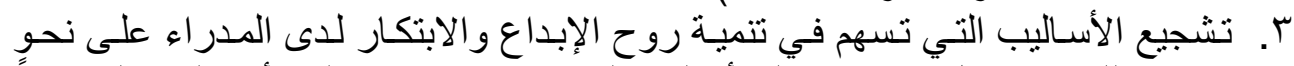

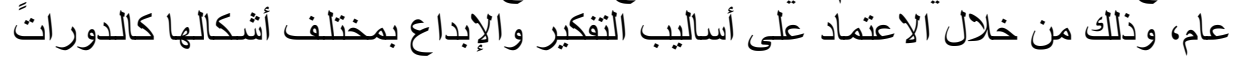
التدريبية (النظرية و العملية) و الطاو لات المستديرة (العصف الإبـ الذهني) و الحوار المتبادل و وغير ذلك. ع. على المنظمات المبحوثة و المنظمات على نحوٍ عام دعم الخصائص الريادية التي تظهر لاى المدر اء أو الأفر ادِ العاملين.

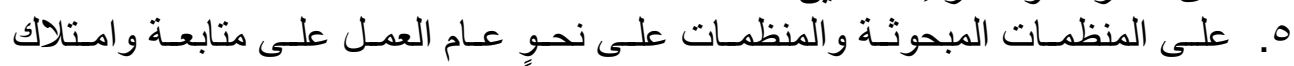

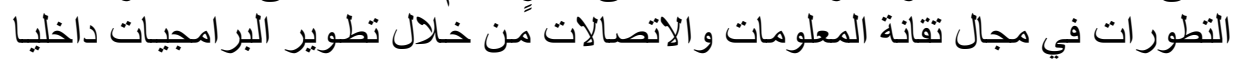

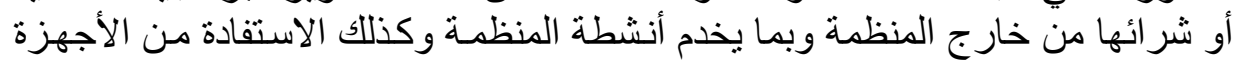

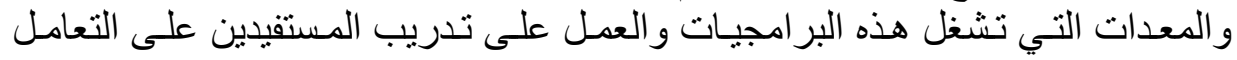
معها.

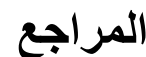

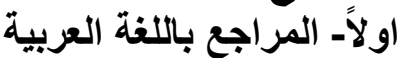

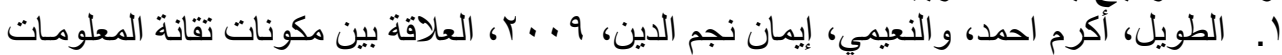

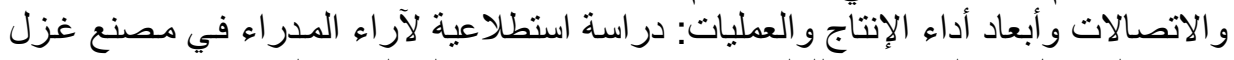

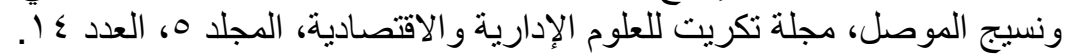

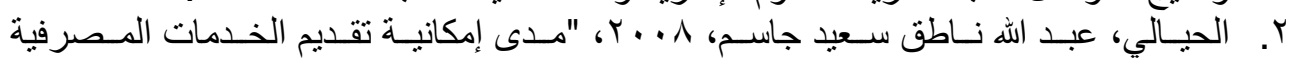

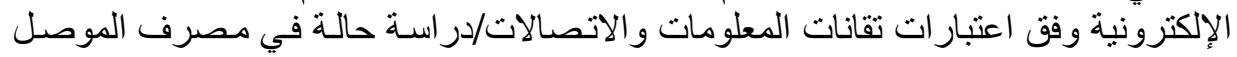

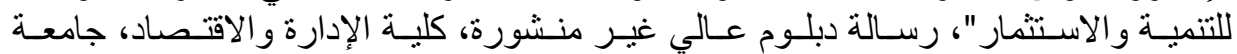

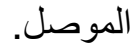

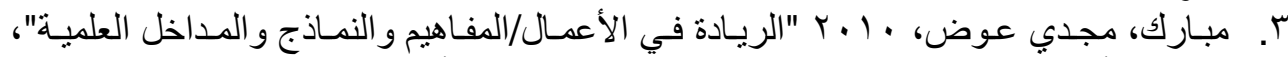

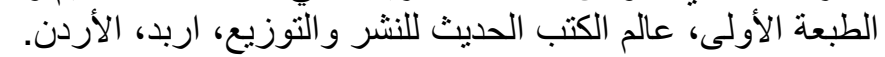

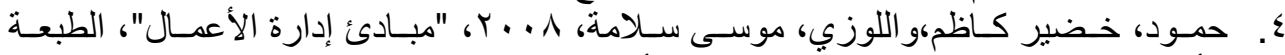

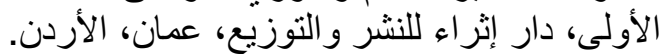

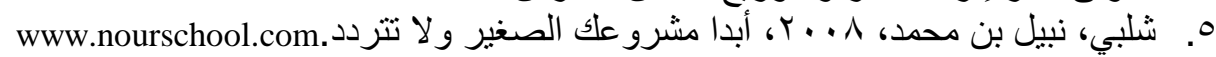

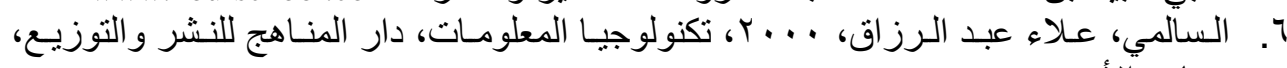
عمان، الأردن. 


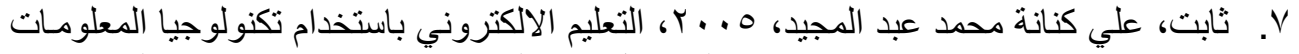

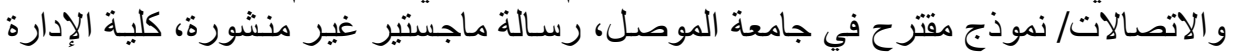

ثانياً. المراجع باللغة الاجنبية

1. Abass, Alya Essam, 2009, Bench Marking Adaptation to Achieve Innovation Case Study in State Company for Leather Industry, Master of Technology in Operations Technologies, Baghdad

2. Abdulla, Syahida, 2008, Technology Entrepreneurship Development In Malaysia: A case study of National Automotive Industry, Ph.D.thesis (www.dspace.fsktm.um.edu.my)

3. Alter, Steven, 1999, Information systems: A management Perspective, $3^{\text {rd }}$ ed, Addition, Wesley Educational publishers.

4. Bateman Thomas SandSnell, Scott A.2007, Leadding and Collaborating in Competitive world, $7^{\text {th }}$ ed, McGraw-Hill, Irwin, Boston.

5. Bateman, ThomasandSnell, Scott, 2007, Management, $7^{\text {th }}$ ed, Irwin Mc Graw-Hill, U.S.A

6. Cleary, Timothy, 1998, Business Information Technology, Prentic-Hill, British.

7. Curtis, Graham, 1995, Business Information system, $2^{\text {nd }}$ ed, Addison Wesley, Publishers Company, Inc, U.S.A

8. Daft, L. Richard, 2001, Organization Theory and Design, $7^{\text {th }}$ ed, south-western, west, U.S.A

9. Daft, L.Richard, 2003, Management, $6^{\text {th }}$ ed, Thomson South-Western, West, U.S.A

10. Daniel, John, 2002, Information and Communication technology in Education, Mariana Patru, UNESCo, Paris, France.

11. Efraim, I and et.al, 1996, Information Technology for Management Improving Quality and Productivity, John Wiley and Sons, Inc.U.S.A

12. Haag, Stephen and Camming, Maeve, 2006, Information Systems Essentioals, McGraw-Hill.U.S.A

13. Haag, Stephen and Cummings, Maeve and Phillips, Amy, 2007, Management Information Systems, $6^{\text {th }}$ ed, Irwin McGraw-Hill, New york, U.S.A

14. Kenneth, C.L.and John, P., 2000, Management Information Systems Organization and Technology in the Network Enterprise, prentice Hill-International, Inc, U.S.A

15. Laudon C. Keneth and Laudon P.Jane, 2000, Management Information Systems, Prentice-Hall International, U.S.A

16. Laudon C. Keneth and Laudon P. Jane, 2002, Management Information Systems Managing Digital Firm, $7^{\text {th }}$ ed, Prentice-Hall International, Inc, U.S.A

17. McKenna, Eugene, 2006, Business Psychology and Organizational Behaviors A Student s Handbook, 4thed, New York, Psyhology Press.

18. Nickerson, C.Robert, 2001, Business and Information Systems, Prentic-Hall, New Jersey.

19. O'Brien, James, 1997, Introduction to Information Systems, $8^{\text {th }}$ ed, Mc Graw-Hill, U.S.A

20. O'Brien, James, 2003, Introduction to Information Systems, $11^{\text {th }}$ ed, Mc Graw-Hill, U.S.A

21. Oz, Effy, 2002, Management Information Systms, $3^{\text {rd }}$ ed, Thomson, Canada.

22. Robbins S., 1990, Organization Theory: Design and Application, prentice-HallInternational.

23. Robert and et. al, 2005, Entrepreneurship, $6^{\text {th }}$ ed, Mc Graw-Hill, U.S.A 


\section{$[1 \cdot v]$ ز}

24. Stair, M. Ralph and Reynolds, W. George, 2003, Principles of Information Systems: A Managerial Approach, $6^{\text {th }}$ ed, Thomson Course, Canada.

25. Turban, Efraim\&et.al, 2002, Information Technology for Management: Transforming Business in Digital Economy, $3^{\text {rd }}$ ed, John Wily \& Aona, Inc

26. F.herbert \& N.link, 2000, In Search of the Meaning of Entreprenurship. www.nap.edu

27. Goldsmith, Peter, 2004, What is Entrepreneurship www.web.extension.uiuc.edu

28. Mishara, Sanjay, 2002, Exploring Entrepreneurship. www.ruddfoundation.org

29. J.Gregory, Dees, 2001, The Meaning of Social.

Entrepreneurship.www.arabschool.org.sy

30. www.papers.ssm.com

31. www.nourschool.com

32. www.sustainablevaluepartners.com

33. www.backercpa.com

34. www.umbb.dz

35. www.mawhiba.org 